\title{
Dynamic Responses Analysis of a 5MW Spar-Type Floating Wind Turbine under Accidental Ship-impact Scenario
}

\author{
Yichi Zhang ${ }^{1}$, Zhiqiang $\mathrm{Hu}^{1,3}$, Chong $\mathrm{Ng}^{2}$, Chunjiang $\mathrm{Jia}^{2}$, Zhe Jiang ${ }^{4}$ \\ 1. School of Engineering, Newcastle University, Newcastle upon Tyne, NE1 7RU, UK \\ 2. Offshore Renewable Energy Catapult, Blyth, NE24 1LZ, UK
}

3. College of Shipbuilding Engineering, Harbin Engineering University, Harbin, 150001, China

4. Shanghai Engineering Research Center of Hadal Science and Technology, Shanghai Ocean University, Shanghai, 201306, China

\begin{abstract}
Ship impact against offshore floating wind turbine (OFWT) has been identified as one of the major hazards with the development of OFWTs. The dynamic responses of OFWTs under ship impact should be taken into consideration during the design phase. This paper addresses a study on the dynamic responses of an OFWT in ship collision scenarios. Firstly, a mathematical model for external mechanism of ship-OFWT collision scenario is developed. Secondly, this model is combined with an in-house programme, DARwind, which can be used to predict nonlinear dynamic responses of whole OFWT system in time-domain. With the newly combined analysis tool, simulation cases for different scenarios are conducted to investigate the nonlinear dynamic responses of OFWT system, including the cases of still water condition, wave-only condition and windwave condition. It is shown that in still water condition, the ship impact will more obviously change the responses of motions and mooring system, compared with those in wave and wave-wind conditions. In the wave-only condition, these motions responses of platform are suppressed by wave effect, but the tower vibration and tower top deformation are sensitive to ship collision. For the wave-wind combined condition, the motions increment in surge and pitch due to ship collision becomes smaller than that of wave-only condition, but yaw motion has a considerable variation compared with those of the other two conditions. Additionally, the blade tip deformation increment due to ship collision are analyzed and it is found that the edgewise tip deformation got more obvious increment than that of flapwise. To further asses the safety of OFWT, the acceleration at nacelle are analyzed because some equipment might be sensitive to acceleration. The analysis results indicate that even though the OFWT structure doesn't get critical damage by ship impact, the equipment inside may still fail to work due to the high value of acceleration induced by ship impact. The research outcomes can benefit the safety design of OFWT in the engineering practice.
\end{abstract}

Keywords: Spar-type floating wind turbine; ship collision; impact dynamic model; global dynamic responses; DARwind

\section{Introduction}

Renewable energy harvesting has always been attractive in the past decade due to the global demand of reducing $\mathrm{CO}_{2} \mathrm{emission}$ Among the various kinds of renewable sources, wind energy is one of the most profitable energies as it is commercialized, clean, inexhaustible and has little pollution. An increasing number of offshore wind farms have been built and the cumulative installed capacity of offshore wind farms has reached $23 \mathrm{GW}$ in 2018 [1]. In the meantime, as the offshore wind farms could be located close to the traffic lines and the offshore service vessels (OSV) must get access to the offshore wind turbine (OWT) to conduct normal maintenance, there does exist a potential ship collision hazard. There are some collision accidents that can be found in the Accident Statistics at Caithness Windfarm Information Forum [6]. On 23 $3^{\text {rd }}$ November 2012, five seamen got injured after their vessel collided with a wind turbine at Sheringham shoal offshore wind farm, England. On $4^{\text {th }}$ April 2014, a crew transfer vessel collided with a wind turbine at high speed in Great Yarmouth offshore wind farm, England. These accidents not only lead to structural damage and economic loss, but also bring human injuries to varying extents.

Therefore, a series of risk analyses have been studied regarding to the problem of ship collision with offshore wind turbines. Christensen et al [2] established a model to evaluate the collision frequencies for the wind farm and different factors, such as ship traffic, navigation routes, geometry of wind farms, were all taken into consideration. Biehl et al. [3] carried out the numerical collision simulations and combined it with statistical data as well as probabilities of occurrence of various scenarios to assess the safety. More recently, Dai et al. [4] and Presencia et al. [5] presented further researches of risk assessment for offshore wind turbine and more scenarios with different types of ships were studied. Their works particularly focus on the collision by service and maintenance vessel respectively as these kinds of ships were thought to be more likely to impact wind turbines due to the need to conduct works within the wind farms.

Some studies focusing on the dynamic responses of OWT in collision scenarios were made on fixed foundation wind turbines. Biehl [7] presented an application of LS-DYNA, a non-linear finite element code, on ship-OWT collision analysis. In this study, the collisions between several common types of OWT and varieties of ships (e.g. single hull tankers, double hull tankers and cargo ships) were analyzed with detailed consideration of features including gravity and loads of turbine, soil interaction. 
Le Sourne and Barrera et al. [8] studied the crashworthiness of a jacket foundation OWT struck by an OSV by means of nonlinear finite element methods (NLFEM). Both rigid and deformable ships were modelled, and a series of factors, such as gravity loads, soil stiffness, were compared to conduct sensitivity analysis on energy dissipation pattern and crushing force. Moulas, et al. [9] also employed NLFE analysis but mainly focused on evaluating the damage of OWT foundation caused by OSV impact. The deformation pattern and damage modes of monopile and jacket type foundations in various collision scenarios were identified and discussed. Bela, et al. [10] studied ship collision particularly with monopile foundation OWT. They have investigated in detail the sensitivity of different parameters, such as impact velocity, impact location, wind effect, soil interaction and deformability of striking ship. In addition, Bela et al.[10] innovatively considered the dynamic responses of nacelle. The displacement as well as accelerations at nacelle (i.e. top of tower) of a monopile OWT were compared and analyzed in different scenarios. The nonlinear finite elements approach is popular for ship-OWT collision analysis as it can give direct sight on structural deformation modes, but it may not be well suited in early design stage due to the large computational cost. Le Sourne et al [31] developed analytical methods based on upper-bound method [11] and Pire et al [12] further derived a series of formulae to assess dissipated energy at the bottom of wind turbine jacket foundation after ship collision. There are existing design standards and guidelines in this area had been developed. Ship collision against offshore wind turbine have been mentioned in DNV-OS-J101 [13]. The design of OWT against ship impacts has been considered in ULS and ALS depending on whether the secondary or primary structure is damaged.

It is noticed that these existing studies mostly focus on the offshore fixed foundation wind turbine, especially the internal dynamics. Offshore floating wind turbine (OFWT), however, still received little attention. Offshore floating wind turbines are normally exposed at further and deeper water zones where larger service vessels are required and could be located closer to the traffic line. Thus, the ship collision risk may increase. There are a few but not adequate studies on ship collisions with floating wind turbines recently. DNV-OS-J103 [14] adopted the same requirements from DNV-OS-J101[13] and applied into floating wind turbines regarding ship collision but DNV-OS-J103 [14] still pointed out that these requirements need to be more thoroughly discussed in the future due to some special and complicated features of floating platform. Echeverry et al. [15] has studied the crashworthiness of a spar-type floating offshore wind turbine under ship collision by numerical simulation methods. Some parameters characterized to floating wind turbine were considered and discussed, such as hydrodynamic forces, ballast mass and mooring line tension. The internal dynamic responses such as energy dissipation, collision force and structural deformation modes were emphasized while the external dynamics, such as 6DOF motions were also calculated. From the study of Echeverry et al. [15], it is interesting to find that ship collision against floating wind turbines are quite different from collision of fixed foundation OWT. Due to more complicated loads and conditions including mooring, wave, etc. the OFWT may not response like a monopile or jacket foundation OWT which only get serious structural deformation or collapse under the huge impact force. In addition to the structural deformation, the floating wind turbine could have large translation and rotation motions in some directions as it is more flexible.

However, previous researches, including Echeverry et al. [15], focused mostly on the structural responses of the Spar platform. Dynamic responses of the other components, such as tower, mooring system, rotor-nacelle assembly, were not analyzed in detail. The kinetic motions of supporting platform and nacelle, and responses of mooring system, tower and blades are also important and are worth investigating. If an OFWT suffers a short-duration and non-critical impact by OSV, the structural damage might not be serious but the system working performance in the following minutes still needs to be checked based on these dynamic responses after impact. The motion of platform due to ship impact will directly change the responses of mooring system and tower, further influence the performance of rotor-nacelle assembly part, meaning that the wind-induced-loads, generator power are changed accordingly. In the meantime, the performance change will conversely affect the tower and platform's responses.

Therefore, in order to have deeper understanding on the dynamic responses of a floating wind turbine system under ship collision scenario, this paper proposes an efficient approach to analyze the global dynamic responses of OFWT after ship collision. The approach contains two parts, a mathematical model for external dynamics of ship-OFWT collision scenarios and DARwind [18], an in-house programme used for prediction of nonlinear dynamic responses of OFWT. With the proposed approach, various collision scenarios with different impact velocity and environmental conditions are compared and analyzed. In sections below, the collision model and fully coupled offshore wind turbine analysis programme will first be introduced and then a description on how to combine them together will be made. Next, with the newly combined programme, a series of collision cases are simulated and the external dynamic responses of a Spar-type floating wind turbine in time-domain analysis are evaluated for different collision scenarios. This research will contribute and benefit the safety design of OFWT in the engineering practice.

\section{Integrated dynamic model of ship-OFWT collision analysis}

To capture the responses of OFWT in and after ship collision, an integrated dynamic model is proposed. As mentioned before, the whole analysis approach includes a dynamic model for ship-OFWT collision and an aero-hydro-servo-elastic fully coupled simulation tool for OFWT. The collision model can predict the external dynamic responses of OFWT when collision ends and then these results can be employed by DARwind, an OFWT simulation tool, to predict the time-series results after collision. In 
the following sub-sections, the collision mathematical model, OFWT simulation tool are first be introduced and followed by the procedures on how to combine them together.

\subsection{Ship-OFWT collision mathematical model}

Stronge's [16] has proposed a 3D impact dynamic model for rigid bodies and Liu and Amdahl[17] further developed it for ship collision application. The ship-OFWT collision mathematical model presented in this sub-section is a further implementation of Stronge's method [16] and Liu and Amdahl's method [17]. Based on these knowledge, the basic assumptions in this study are applied as below.

- The collision duration is short and the global motions during collision process are small enough to be neglected.

- The collision force is much larger than other forces so that other external forces is temporarily neglected during collision.

- The striking position is on supporting platform only, which means the structural deformations are limited to a small zone within the contact area of platform. In addition, the influences of structural damage of platform do not play a dominating role in this study.

- The operating performance of the OFWT is assumed remain unchanged during the period of analysis, as the change of operation order on OFWT is mostly a gradual process.

The collision between an offshore service vessel and a 5MW OC3 Spar-type floating wind turbine is chosen as the reference target, shown as Figure 1. Two global coordinate systems are used, of which the origins are located at the COG (centre of gravity) of a vessel and the OFWT at the beginning of collision, respectively. A set of mutually perpendicular unit vectors $\overrightarrow{n_{1}}, \overrightarrow{n_{2}}, \overrightarrow{n_{3}}$ are used and the vectors $\overrightarrow{n_{1}}$ and $\overrightarrow{n_{2}}$ are in the common tangent plane at collision point $\mathrm{C}$ while $\overrightarrow{n_{3}}$ is normal to this plane. Then a local coordinate system $\left(\overrightarrow{n_{1}}, \overrightarrow{n_{2}}, \overrightarrow{n_{3}}\right)$ is established. To distinguish the variables from different bodies, the prime mark ' is used to indicates variables of the ship. Direction vectors from COG of each body to the collision point are represented separately as $r$ and $r^{\prime}$.

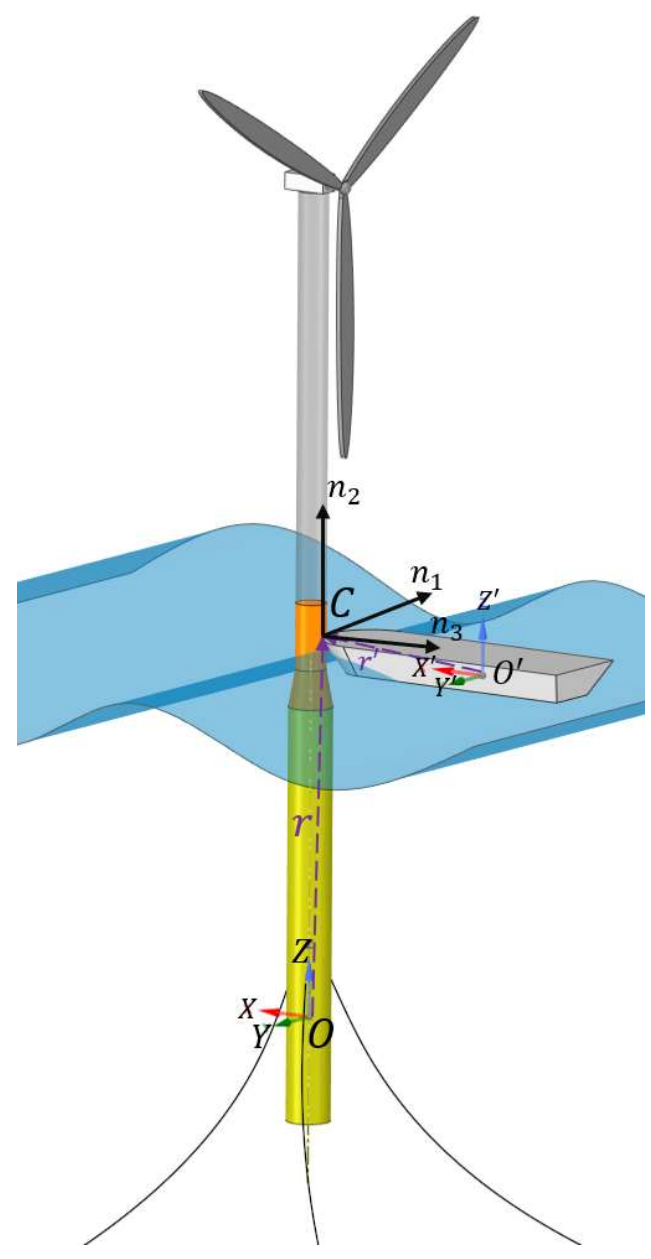

Figure 1. Coordinated systems definition in ship-OFWT collision model. 
At the collision point $\mathrm{C}$, the OFWT and ship are undertaken mutual impact forces $F, F^{\prime}$ so the impulses to each body are written as

$$
\begin{aligned}
\mathrm{d} P_{i} & =F_{i} d t \\
\mathrm{~d} P_{i}^{\prime} & =F_{i}^{\prime} d t
\end{aligned}
$$

Thus, the equations for translation and rotational motions are expressed as

$\operatorname{Md} V_{i}=F_{i} d t$

$I_{i j} d \omega_{j}=\varepsilon_{i j k} r_{j} d P_{k}$

and

$\mathrm{M}^{\prime} \mathrm{d} V_{i}^{\prime}=F_{i}^{\prime} d t$

$I_{i j}^{\prime} d \omega_{j}^{\prime}=\varepsilon_{i j k} r_{j}^{\prime} d P_{k}^{\prime}$

where $V_{i}$ and $V_{i}^{\prime}$ represent the velocities at COG of each body while $\omega_{i}$ and $\omega_{i}^{\prime}$ are their angular velocities in the direction of $\overrightarrow{n_{l}}$ in the local coordinate system. Based on the assumptions mentioned above, due to the large collision forces, all the other external forces can be neglected for the time being so that $F, F^{\prime}$ here only indicated the collision force. $\mathrm{M}, \mathrm{M}^{\prime}$ and $I_{i j}$, $I_{i j}^{\prime}$ refers to the mass and second moment of OFWT and ship, respectively. To consider the effects of surrounding fluid, the added mass coefficient and added inertia coefficient are introduced to the mass matrices and inertia matrices. The above equations are written in Einstein summation convention and $\varepsilon_{i j k}$ is Levi-Civita symbol and it equals to +1 if the indices are in cyclic order and -1 for anticyclic order and 0 if the value of any indices are the same. The subscript $i, j$ of velocity and angular velocity refer to the $i^{\text {th }}$ and $j^{\text {th }}$ component of them.

Next, the velocities of these two bodies at the collision point $C$ can be expressed as follows according to the velocity relationship between two points on a rigid body of supporting platform.

$V_{c i}=V_{i}+\varepsilon_{i j k} \omega_{j} r_{k} \quad(i, j, k=1,2,3)$

$V_{c i}^{\prime}=V_{i}^{\prime}+\varepsilon_{i j k} \omega_{j}^{\prime} r_{k}^{\prime} \quad(i, j, k=1,2,3)$

Then the relative velocity is obtained as

$v_{i}=V_{c i}-V_{c i}^{\prime}$

As the deformation is assumed to be limited in a very small area at the collision point, the mass of the deforming part can be neglected. Therefore, the incremental change in the reaction impulses is equal in magnitude but in converse direction. Thus, it can be expressed as

$d p_{i}=d P_{i}=-d P_{i}^{\prime}$

From equations (1) - (10), we finally have

$\mathrm{d} v_{i}=m_{i j}^{-1} d p_{j}$

where

$m_{i j}^{-1}=\left(M_{i j}^{-1}+M_{i j}^{\prime-1}\right)+\varepsilon_{i k m} \varepsilon_{j l n}\left(I_{k l}^{-1} r_{m} r_{n}+I^{\prime-1}{ }_{k l}^{\prime} r_{m}^{\prime} r_{n}^{\prime}\right)$

The change of relative velocity can be expressed as 
where $v_{i}^{t}$ refers to relative velocity in $\overrightarrow{n_{l}}$ direction when collision ends and $v_{i}^{0}$ indicates relative velocity when collision occurs. If we ignore the possible repetitive impacts and assume there's no sliding between OFWT and ship during the collision, then the relative velocity after collision can be expressed.

$v_{i}^{t}= \begin{cases}0 & i=1 \\ 0 & i=2 \\ -e v_{3}^{0} & i=3\end{cases}$

In the above equations, $e$ is defined as coefficient of restitution and usually varies from 0 to 1 . It equals to 0 when the perfect plastic collision occurs and equals 1 in the perfect elastic collision.

After obtaining the incremental change of relative velocity, the change of impulse can be calculated according to equation (11) and then the change of velocity as well as angular velocity of OFWT are obtained according to equations (5) and (6). Finally, the velocity and angular velocity of OFWT after collision can be expressed as

$\begin{array}{ll}V_{i}^{t}=V_{i}+d V_{i} & i=1,2,3 \\ \omega_{i}^{t}=\omega_{i}+d \omega_{i} & i=1,2,3\end{array}$

It is noticed that the calculations are conducted in the local coordinate system $\left(\overrightarrow{n_{1}}, \overrightarrow{n_{2}}, \overrightarrow{n_{3}}\right)$. Thus, some transformation matrices need to be derived and these will be presented in section 2.3

\subsection{Fully-coupled analysis methods for OFWT}

DARwind is used in this study for the dynamic responses analysis of the system after impact. It is an intergrade programme based on full-coupled aero-hydro-servo-elastic methods for the simulation of offshore wind turbine developed by Chen and Hu. et al. [18] and some key theoretical background is introduced in this section.

In the programme, hybrid coordinate dynamical analysis method [19] and cardan angle methods [20] are adopted to describe the kinematics of OFWT. Hybrid coordinate dynamical analysis method is for describing the translational motion of the rigidflexible coupled multi-body system of OFWT. Two types of coordinate system are defined in this method, of which one is the global reference frame for describing the location of the bodies and the other one is called local elastic body-fixed frame (also called floating frame). Cardan angles coordinate is used to describe the rotational motion of OFWT. As a limited rotation of a body about one point can be decomposed as three limited angles corresponding to three different coordinated axes [32], the following steps are presented to define Cardan angles. As is illustrated in Figure 2, in the first step, the body fixed frame $e^{(0)}$ rotates an angle of $\alpha$ about its axis $e_{1}^{(0)}$ and then frame $e^{(1)}$ is obtained. Secondly, the frame $e^{(1)}$ will rotate about its axis $e_{2}^{(1)}$ for an angle of $\beta$ to frame $e^{(2)}$. Finally, the frame $e^{(2)}$ rotates about axis $e_{3}^{(2)}$ to frame $e^{(3)}$ at an angle of $\gamma$. These three rotated angles are called cardan angles.

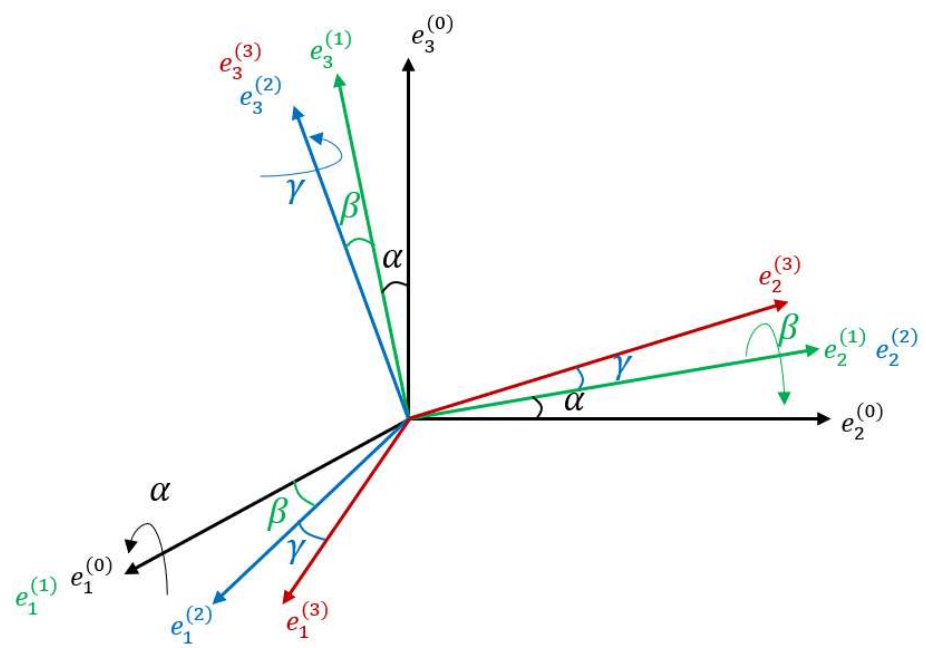

Figure 2. Cardan angles illustration 
In DARwind, aerodynamic loads at rotor plane are mainly calculated with Blade Element Momentum (BEM) method [21] including some aerodynamic corrections, such as Prandtl's tip-loss and hub-loss corrections [21], Glauert's corrections [34], dynamic wake corrections [35], etc. BEM method is essentially a combination of 1-D momentum theory and 2-D blade element theory. In 1-D momentum theory, the rotor is assumed to be a permeable frictionless disc and part of the momentum of the inflow will be lost when it passes through the rotor plane. In 2-D blade element theory, it is assumed that the blades are divided into many elements and the aerodynamic loads acting on these elements are calculated respectively. In addition, aerodynamic loads of the tower are calculated by summarizing the aerodynamic load at the midpoints of all discrete element

$d F^{T}=\frac{1}{2} \rho C_{d} \delta L D\left(V_{0}^{\text {wind }}-V_{T E}\right)\left|V_{0}^{\text {wind }}-V_{T E}\right|$

where $C_{d}$ is the drag coefficient, D is the diameter of section of the current element, $V_{0}^{\text {wind }}$ is the upwind speed and $V_{T E}$ is the velocity of tower element.

As per hydrodynamic loads, linear wave theory [33] is used to model the wave and diffraction, radiation as well as hydrostatic problems are all considered. The required hydrodynamic coefficients to calculate hydrodynamic loads in DARwind code can be obtained from 3-D panel-based hydrodynamic analysis program, WAMIT or SESAM. The total hydrodynamic loads thus can be written as:

$F_{H}=F^{W}+F_{s e c}^{W}+F^{R}+F^{s}+F^{V}$

where $F^{W}$ is the excitation force calculated by harmonic superposition method, $F_{s e c}^{W}$ is the second-order wave force consisting of sum-frequency and difference-frequency wave forces components. $F^{s}$ refers to the buoyancy as well as hydrostatic restoring forces and $F^{V}$ is the horizontal nonlinear viscous damping force calculated by Morison's equation. $F^{R}$ is the linear wave radiation force with free-surface memory effects, given by

$F_{j}^{R}(t)=-\sum_{k=1}^{6}\left\{\mu_{j k}(\infty) \ddot{x}_{k}(t)+\int_{-\infty}^{t} K_{j k}(t-\tau) \dot{x}_{k}(\tau) d \tau\right\}, \quad j=1,2 \ldots, 6$

where $\mu_{j k}(\infty)$ is the added mass coefficient corresponding to infinite frequency and the second term on the right side is the potential damping.

In the mooring dynamics module, a catenary mooring system is modelled and quasi-static approach [22] is employed in the code. The mooring lines are assumed to be in static equilibrium at any time with stretching force but some dynamical properties such as the inertia and damping are not considered. For conciseness, the formulae are not presented and the detailed derivation can be referred to Chen and $\mathrm{Hu}$ et al.[18].

After introducing some key modules in DARwind code, the whole analysis procedures of DARwind are illustrated as Figure 3. As is presented in the flow chart, all types of loads are calculated at each time step firstly. Then Kane's equation method [23] is applied to establish the dynamic equation for the whole multi-body system and generalized accelerations are then calculated. Finally, with the Runge-kutta method, the above calculation procedures are repeated until the terminative time set by the users.

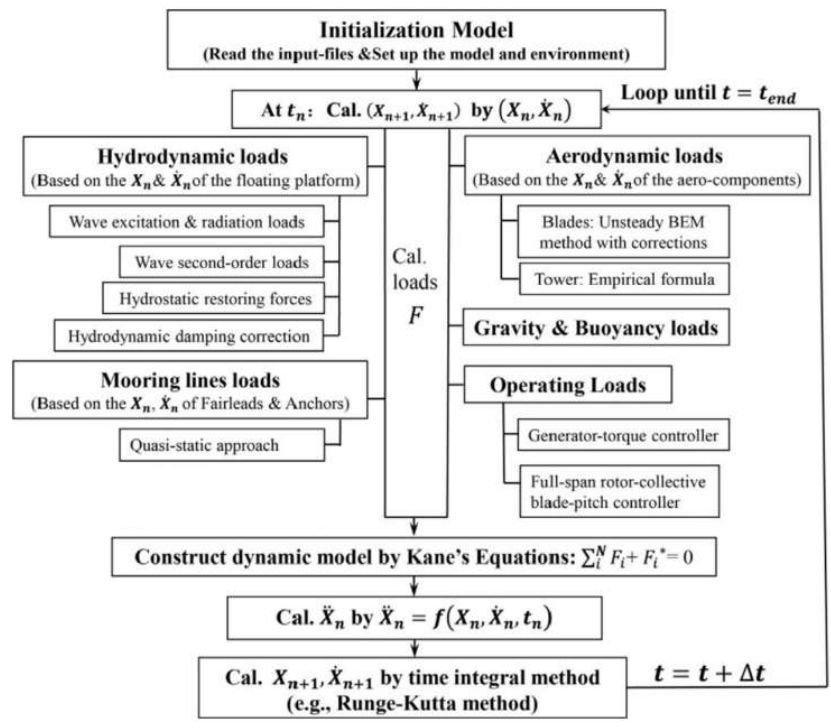


Figure 3, the illustration of analysis procedure of DARwind from Chen and $\mathrm{Hu}$ et al. [18]

\subsection{Transformation matrix}

As the calculation method of ship-OFWT collision is based on the local coordinate system but the velocities of ship and OFWT we described are in their own global coordinate system. Thus, a series of transformation matrices need to be derived.

Also, if an OFWT is working under wave-wind condition, then before the moment of ship impact, OFWT may not be in an upright stance and could have some rotation motions. Thus, the derivation of transformation matrices for OFWT which have general rotational motions will be presented. According to description in sub-section 2.1, the global and local coordinate systems set in collision model are illustrated as Figure 4. Figure 4(b) is the cross-section in $X O Y$ plane and $\alpha^{\prime}$ is the angle that $X$-axis sweeps when it rotates about $Z$-axis to the projection of direction vector $r$ in $X O Y$ plane.

By calculating the direction cosines between the axes of OFWT global and local coordinate systems such as

$$
\begin{aligned}
& \cos \left(\vec{X}, \overrightarrow{n_{1}}\right)=\cos \left(\alpha^{\prime}+\frac{\pi}{2}\right)=-\sin \left(\alpha^{\prime}\right) \\
& \cos \left(\vec{X}, \overrightarrow{n_{2}}\right)=0 \\
& \cos \left(\vec{X}, \overrightarrow{n_{3}}\right)=\cos \left(\alpha^{\prime}\right)
\end{aligned}
$$

Then whole transformation matrix from OFWT global coordinates to local coordinates can be written as

$T_{O L}=\left[\begin{array}{ccc}-\sin \alpha^{\prime} & 0 & \cos \alpha^{\prime} \\ \cos \alpha^{\prime} & 0 & \sin \alpha^{\prime} \\ 0 & 1 & 0\end{array}\right]$

However, the velocities output from DARwind are in its global coordinate system and this is different from the global coordinate system in collision model. To distinguish them, a note will be added in the bracket following the coordinate system. For example, global coordinate system (DARwind), global coordinate system (collision).

The global coordinate system (DARwind) is fixed at the interface between the still water level and the initial centreline of the floating platform and the global coordinate system (collision) indeed coincides with the body-fixed frame of floating platform, which rotates with the platform at the moment that collision occurs. Therefore, a transformation matrix from global coordinate system (DARwind) to global coordinate system (collision) needs to be derived.

As is introduced before, the cardan angles method is adopted to describe the rotational motion of OFWT in DARwind, the required matrix above is indeed the transformation matrix from frame $e^{(0)}$ to $e^{(3)}$, given by

$T_{03}=T_{01} T_{12} T_{23}$

where

$$
\begin{aligned}
T_{01} & =\left[\begin{array}{ccc}
1 & 0 & 0 \\
0 & \cos \alpha & -\sin \alpha \\
0 & \sin \alpha & \cos \alpha
\end{array}\right] \\
T_{12} & =\left[\begin{array}{ccc}
\cos \beta & 0 & \sin \beta \\
0 & 1 & 0 \\
-\sin \beta & 0 & \cos \beta
\end{array}\right] \\
T_{23} & =\left[\begin{array}{ccc}
\cos \gamma & -\sin \gamma & 0 \\
\sin \gamma & \cos \gamma & 0 \\
0 & 0 & 1
\end{array}\right]
\end{aligned}
$$

Therefore, the transformation matrix from global coordinate system (DARwind) to local coordinate system at collision point $\mathrm{C}$ is obtained

$T_{D L}=T_{03} T_{O L}$ 
Next, let's focus on the transformation matrices for ship. To simplify the problem and only focus on OFWT, the ship is assumed to be in the upright floating position (no rotational motions) and only have forward speed before the collision. It's complicated to directly transform the data of ship from its global coordinate system to the local coordinate system, so it is divided into several steps to finish.

Firstly, we assume the OFWT at an un-rotated position, and then the transformation matrix from global coordinate system of ship to the body-fixed frame of OFWT at this moment can be obtained according to the illustration of Figure 5.

$T_{S O}=\left[\begin{array}{ccc}\cos \theta & \sin \theta & 0 \\ -\sin \theta & \cos \theta & 0 \\ 0 & 0 & 1\end{array}\right]$

Secondly, we will transform the data of ship from the body-fixed frame of OFWT at un-rotated position to the body-fixed frame of OFWT at its real position. This transformation matrix is given by $T_{03}$ as well.

Finally, the data of ship will be transformed to the local coordinate system from the body-fixed frame of OFWT. The transformation matrix is the same as $T_{O L}$. Therefore, the final transformation matrix of ship from its own global coordinate system to the local coordinate system at collision point are obtained as

$T_{S L}=T_{S O} T_{03} T_{O L}=T_{S O} T_{D L}$

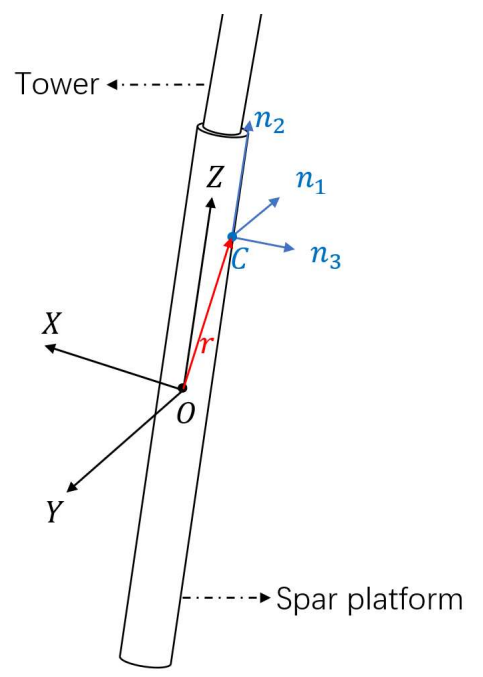

(a) Coordinate systems on a general stance of OFWT

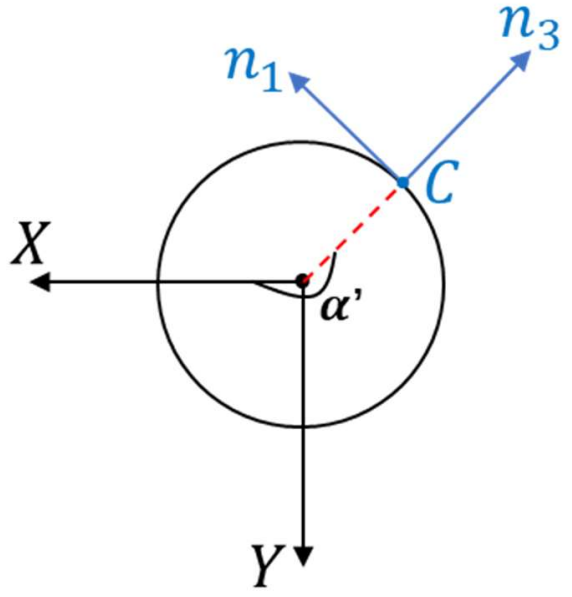

(b) Cross-section view in XOY plane.

Figure 4. Illustration of coordinate systems and angles for OFWT.

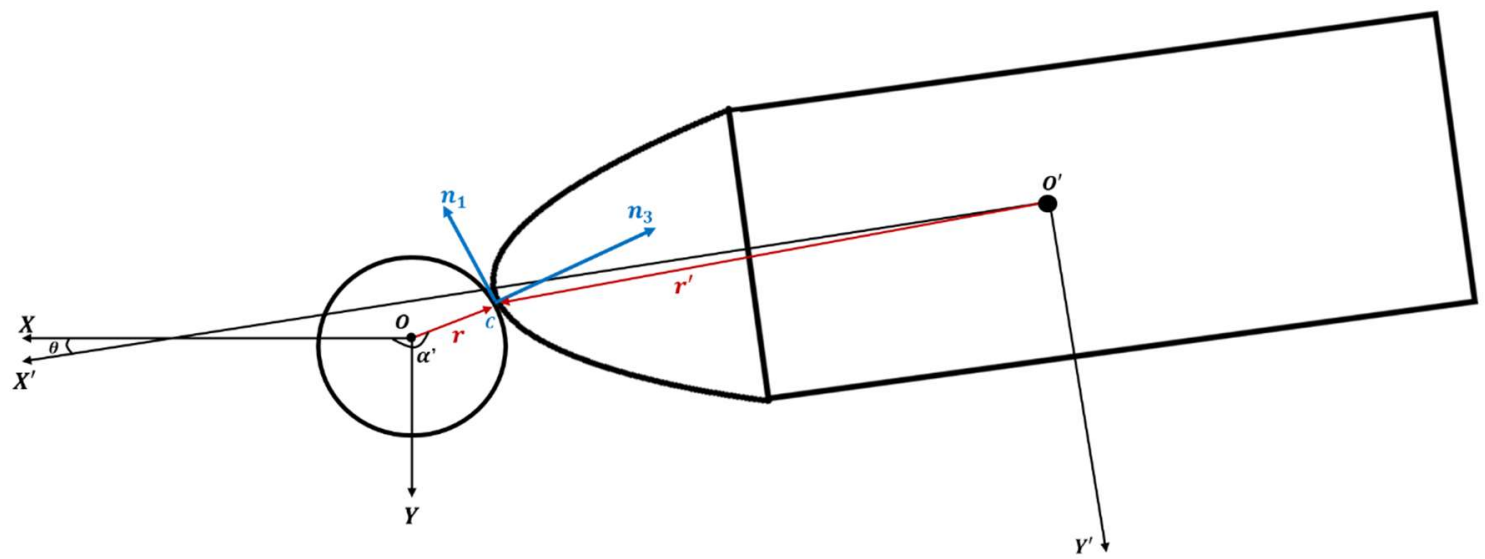

Figure 5. 2D Illustration of ship collision against an upright floating spar floating wind turbine.

As the transformation matrices have all been derived above, some examples of using these transformation matrices are presented below. $V_{\text {global }}$ refers to the velocities directly output from DARwind and other parameters are already expressed under the global coordinates in collision model, so the transformation matrix $T_{O L}$ rather than $T_{D L}$ is used for them 


$$
\begin{aligned}
& V_{\text {local }}=T_{D L}^{-1} \bullet V_{\text {global }} \\
& r_{\text {local }}=T_{O L}^{-1} \cdot r_{\text {global }} \\
& M_{\text {local }}=T_{O L}^{-1} \bullet M_{\text {global }} \bullet T_{O L} \\
& I_{\text {local }}=T_{O L}^{-1} \bullet I_{\text {global }} \bullet T_{O L}
\end{aligned}
$$

\subsection{Integrated collision analysis methods}

In section 2.1, a mathematical model is built based on the 3D ship-OWFT collision scenario but it only addresses the problem of kinematic characters during the collision moment. To have deeper understanding of the dynamic responses of OFWT during and after ship impact. The proposed mathematical collision model and DAR wind programme are integrated as a new numerical tool. The main analyzing procedure is shown in Figure 6, and described below as well

Firstly, the input data is initialized and then a period of simulation for OFWT is conducted by DARwind until collision occurs at $t_{0}$.

Following the step 2, the results during $0-t_{0}$ are saved and in the meantime, the dynamic responses output from DARwind at $t_{0}$ will be extracted. From this moment, $t_{0}$, the ship impact occurs, so the required data for collision calculation, including the current position and velocities of OFWT and ship in $6 \mathrm{DOF}$, will be input to the $3 \mathrm{D}$ collision analysis program, as shown in step 4.

Afterwards, the velocities of OFWT after collision are calculated by the collision model and only the dynamic responses of OFWT are focused then. Due to extremely short collision duration, the moment before and after collision are districted as $t_{0}^{-}$, $t_{0}^{+}$. Only the velocities at $t_{0}^{+}$are thought to be changed due to the ship impact while other parameters of OFWT at $t_{0}^{+}$, such as platform location, aerodynamic loads, power, etc. are thought to keep the same. Therefore, a series of new input data are formed following step 6 by combining the dynamic responses results at $t_{0}^{-}$and $t_{0}^{+}$. Indeed, the new input file keeps the same as the results at $t_{0}^{-}$except for the platform velocities which are replaced by those after collision obtained in step 5 .

With the new input file, a new period of $t_{1}$ simulation for OFWT will be conducted and the results during this period can be output. Finally, in step 8 , we integrate the results of $0-t_{0}$ and $t_{0}-t_{1}$ to obtain a complete time-domain results. What need to be noted is that the results at $t_{0}$ should use the data of $t_{0}^{+}$rather than $t_{0}^{-}$.

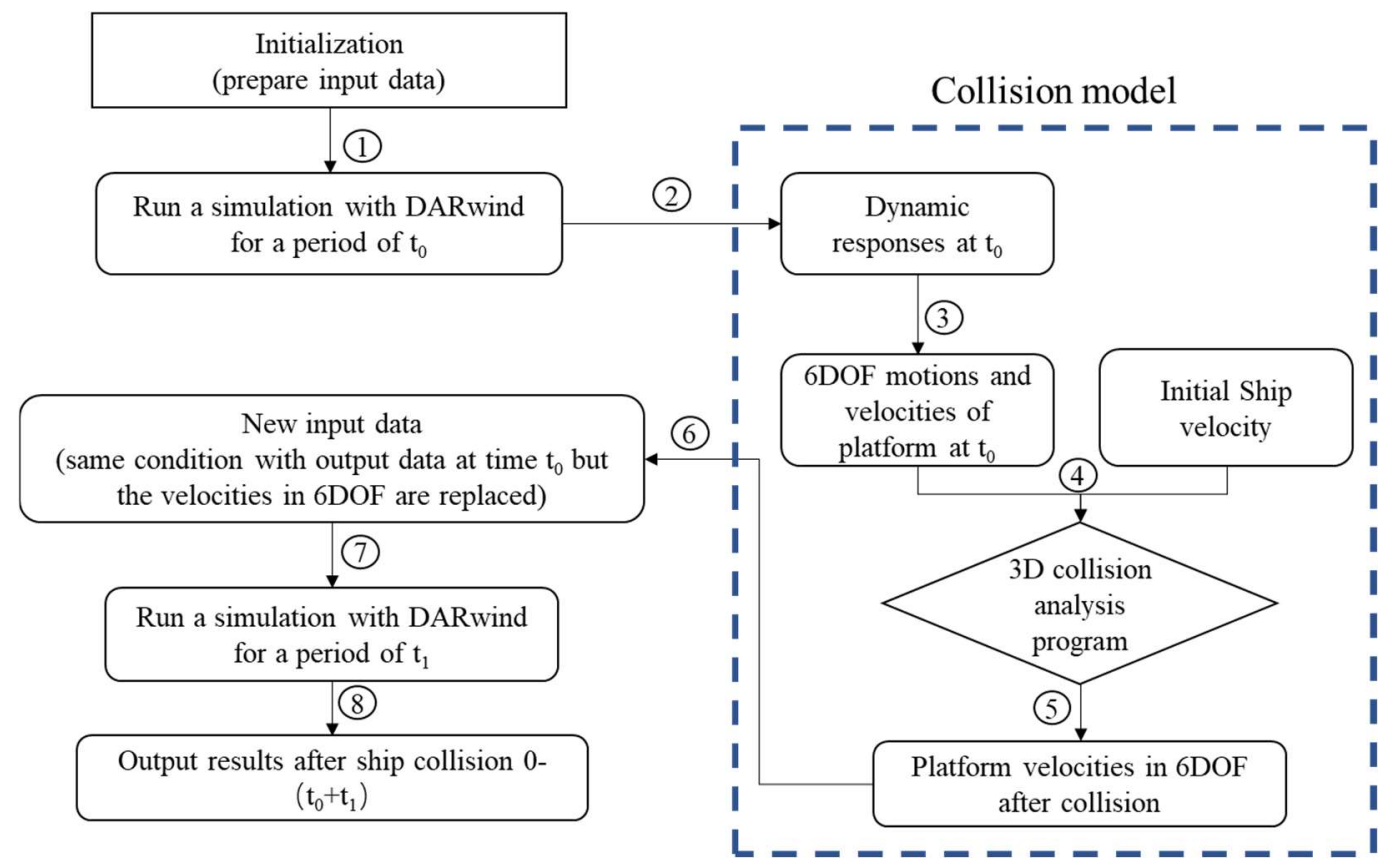

Figure 6, The overall flowchart for analyzing dynamic resposnses of OFWT impact by a ship.

\section{Case studies, results and discussions}




\subsection{Configurations of OFWT and striking OSV}

A 5-MW OC3 Hywind Spar-type floating wind turbine [24,25] and an offshore service vessel are selected. The main properties of them are shown in Table 1 and Table 2.

Table 1. Main properties of OFWT.

\begin{tabular}{lr}
\hline & Offshore floating wind turbine \\
\hline Tower base above SWL & $10 \mathrm{~m}$ \\
Tower top above SWL & $87.6 \mathrm{~m}$ \\
CM of tower above SWL & $43.4 \mathrm{~m}$ \\
Total draft & $120 \mathrm{~m}$ \\
Platform top above SWL & $10 \mathrm{~m}$ \\
Taper top below SWL & $4 \mathrm{~m}$ \\
Taper bottom below SWL & $12 \mathrm{~m}$ \\
Platform diameter above taper & $6.5 \mathrm{~m}$ \\
Platform diameter below taper & $9.4 \mathrm{~m}$ \\
CM of platform below SWL & $89.9 \mathrm{~m}$ \\
Water depth & $320 \mathrm{~m}$ \\
Number of mooring lines & 3 \\
Depth to fairleads below SWL & $70 \mathrm{~m}$ \\
Radius to anchors from platform centerline & $853.87 \mathrm{~m}$ \\
Unstretched mooring line length & $902.2 \mathrm{~m}$ \\
Total mass (including ballast, tower, nacelle, rotor, blades) & 8066 tons \\
\hline
\end{tabular}

Table 2. Main properties of OSV.

\begin{tabular}{lr}
\hline \multicolumn{2}{c}{ Offshore service vessel } \\
\hline L.O.A & $72.2 \mathrm{~m}$ \\
Beam & $16 \mathrm{~m}$ \\
Depth & $7.55 / 11 \mathrm{~m}$ \\
Draft & $5.4 \mathrm{~m}$ \\
Displacement & 4,000 tons \\
\hline
\end{tabular}

In the collision model described in section 2.1, added mass coefficients of ship and OFWT in 6DOF are required to consider the surrounded fluid effects. In the following case studies, the added mass coefficients are obtained as follows.

For the ship, the added mass coefficients are mainly estimated based on previous studies. According to Petersen and Pedersen. [26], the constant added mass coefficients of ship used in the ship collision analysis depend on the impact duration and they also gave the empirical formula and varying range. For simplicity, $a_{11}=0.05$ and $a_{22}=0.7$ are selected in this paper. Pedersen et al. [27] gave a value of $a_{66}=0.21$ for added mass coefficient in yaw motion during collision. The other three added mass coefficients used in collision analysis are estimated by the empirical formulae from Popov et al.[28]. As for added mass of OFWT in the collision analysis, the value corresponding to infinite frequency are chosen and these can be found from Jonkman's study [24]. The coefficient of restitution, $e=0.5$ will be adopted in the following collision analysis in section 3.3 , 3.4 and 3.5, implying the collision including both plastic and elastic structural deformation but global dynamic responses will be more focused here.

A brief case definition is listed as table 3, where $H$ and $T$ are the wave height and wave period. In the following cases, only head-on collisions are applied. Additionally, the ship impact, wave propagation and wind all have the same direction, along the positive direction of surge motion of OFWT. 
In still water case, the OFWT is assumed to stay static and have no rotational or translational motions when collision occurs. According to the current designing standard [13], the impact velocity should be considered no less than $0.5 \mathrm{~m} / \mathrm{s}$. Thus, in still water situation, the ship is given varying velocities from $1 \mathrm{~m} / \mathrm{s}$ to $3 \mathrm{~m} / \mathrm{s}$ to investigate the influence of impact velocity. For collisions in regular wave and wave-wind condition, the OFWT has got certain motions and velocities when collision occurs and in order to get general sight on the dynamic responses in these environmental conditions, ship collision are set up to occur when OFWT have different motions, corresponding to cases $\mathrm{C} 1-\mathrm{C} 4$ and $\mathrm{C} 5-\mathrm{C} 9$ in these two different environmental conditions.

Table 3. Collision scenarios and cases definition

\begin{tabular}{|c|c|c|c|c|c|}
\hline Case number & Case types & $H(m)$ & $T(s)$ & Wind speed $(\mathrm{m} / \mathrm{s})$ & Ship velocity $(\mathrm{m} / \mathrm{s})$ \\
\hline $\mathrm{C} 0$ & Still water & - & - & - & from 1 to 3 \\
\hline $\mathrm{C} 1-\mathrm{C} 4$ & $\begin{array}{l}\text { Regular wave (different initial motions when } \\
\text { collision occurs) }\end{array}$ & 4 & 10 & - & 3 \\
\hline $\mathrm{C} 5-\mathrm{C} 9$ & $\begin{array}{l}\text { Wind and regular wave (different initial } \\
\text { motions when collision occurs) }\end{array}$ & 4 & 10 & 11.4 & 3 \\
\hline
\end{tabular}

\subsection{Verification}

The proposed method and code are verified in this section. As DARwind has been verified by code-code comparison and experiment validation [18], it is a reliable simulation tool for OFWT dynamic response analysis. Therefore, in this section, the ship-OFWT collision model is verified by comparing the results with an analytical solution for ship-spar collision from Jonge and Laukeland [36]. As the velocities after ship collision can be obtained following the methods described in section 2.1, the energy dissipation can be estimated as

$E_{d}=E_{\text {total }}-\left(E_{s k}+E_{f k}\right)$

where $E_{\text {total }}$ is the total impact energy before collision and $E_{s k}, E_{f k}$ represent the kinetic energy of ship and floating wind turbine after impact, respectively. They are given as

$$
\begin{aligned}
& E_{s k}=\sum_{i=1}^{3} \frac{1}{2} M^{\prime}\left(1+a_{i}{ }^{\prime}\right) V_{i}{ }^{2}+\sum_{i=1}^{3} \frac{1}{2} I_{i}{ }^{\prime}\left(1+j_{i}{ }^{\prime}\right) \omega_{i}{ }^{2} \\
& E_{f k}=\sum_{i=1}^{3} \frac{1}{2} M\left(1+a_{i}\right) V_{i}{ }^{2}+\sum_{i=1}^{3} \frac{1}{2} I_{i}\left(1+j_{i}\right) \omega_{i}^{2}
\end{aligned}
$$

Where $M$ and $I_{i}$ are the mass and inertia moment, $a_{i}$ and $j_{i}$ are the added mass coefficient and added inertia coefficient. The prime mark' indicates the data of ship.

From Jonge and Laukeland's study [36], for head on collision, the dissipated energy are calculated as

$E=\frac{1}{2}\left[\frac{m_{a}\left(1+a_{a}\right) v_{a 0}{ }^{2}}{1+\frac{m_{a}\left(1+a_{a}\right)}{m_{b}\left(1+a_{b}\right)}+\frac{m_{a}\left(1+a_{a}\right) R^{2}}{I_{b}}}\right]$

where $m_{a}, m_{b}$ are the mass of ship and spar, respectively. $a_{a}, a_{b}$ are the added mass coefficients and $v_{a 0}$ is the initial impact velocity. R indicates the distance between collision point and CM while $I_{b}$ is the inertia moment around horizontal axis of spar including added inertia.

The results under different impact velocities and at different collision height are compared in Table 4. It is found that the results from two methods match well, with only a slight difference about $1 \%$ error shown between the two methods, which implies that the present method has the capacity to evaluate the responses between ship and spar-type floating wind turbine. It is also interesting to find that the energy dissipation predicted from present method are less than that of the reference. This is 
due to the 3D model used in present method, 6DOF motions can all be predicted in the present method while motions in vertical plane are considered in Jonge and Laukeland's method. The lack of motions in some degrees of freedom will result in smaller kinetic energy predicted after collision, so the dissipated energy will be larger than that of the proposed method.

Table 4 Comparison of results from current method and Jonge \& Laukeland's method.

\begin{tabular}{|c|c|c|c|c|c|c|c|c|}
\hline \multicolumn{9}{|c|}{ Energy dissipation (MJ) } \\
\hline \multirow{2}{*}{ Impact velocity } & \multicolumn{2}{|c|}{$1 \mathrm{~m} / \mathrm{s}$} & \multicolumn{2}{|c|}{$1.5 \mathrm{~m} / \mathrm{s}$} & \multicolumn{2}{|c|}{$2 \mathrm{~m} / \mathrm{s}$} & \multicolumn{2}{|c|}{$2.5 \mathrm{~m} / \mathrm{s}$} \\
\hline & Present & $\begin{array}{c}\text { Jonge \& } \\
\text { Laukeland }\end{array}$ & Present & $\begin{array}{c}\text { Jonge \& } \\
\text { Laukeland }\end{array}$ & Present & $\begin{array}{c}\text { Jonge \& } \\
\text { Laukeland }\end{array}$ & Present & $\begin{array}{c}\text { Jonge \& } \\
\text { Laukeland }\end{array}$ \\
\hline $3 \mathrm{~m}$ above $\mathrm{SWL}$ & 1.189 & 1.201 & 2.675 & 2.702 & 4.756 & 4.804 & 7.431 & 7.506 \\
\hline $4 \mathrm{~m}$ above $\mathrm{SWL}$ & 1.181 & 1.193 & 2.657 & 2.684 & 4.724 & 4.771 & 7.381 & 7.455 \\
\hline $5 \mathrm{~m}$ above $\mathrm{SWL}$ & 1.173 & 1.184 & 2.639 & 2.665 & 4.692 & 4.738 & 7.331 & 7.404 \\
\hline
\end{tabular}

\subsection{Collision in still water condition}

As the impact direction is along the positive direction of surge motion of OFWT, so the most obvious motion responses should appear in surge and pitch directions, shown as Figure 7 and the collision occurs and ends at the moment when $t=0$ s.

For all pitch motions with different impact velocities, the same trends are found, shown as Figure 7 (a). It could be simple to understand that undertaking the ship impact, the OFWT gets considerable amount of kinetic energy and the pitch motion is then excited due to the vertical eccentricity (vertical distance between COG and collision point). The motion responses after ship collision in the still water can be regarded as a free-decay trend with an initial velocity, which is given by ship impact. Therefore, the presented sinusoid of pitch motion can be explained.

For surge motions after collision, presented as Figure 7 (b), they show a quite different trend, not the sinusoid though they are regarded as free-decay motions with initial velocity. This is mainly caused by the coupling effects with pitch motion. As the dynamical reference point of the platform is set at centre of section at still water level when it is un-moved, the pitch motion will no doubt result in the movement of dynamical reference point, which is reflected by the change of surge motion. Besides, the ship impact will result in pure translation motions in surge direction, which moves the dynamical reference point as well. When these two kinds of motions are coupled, the surge motion reflected in the figure are no longer sinusoid. it is interesting to find the surge motion curves have two crests during the first 40 seconds after collision and the time point of these two crests (about $10^{\text {th }}$ second and $40^{\text {th }}$ second) almost corresponds to the time points, where the maximum pitch angles are reached. This indeed prove the coupling effects of pitch motion as well.

Though different pattern of surge and pitch motion curves are found and discussed, the overall trend of them both shows periodically decay trends under the combination effects of mooring system and hydro loads. Additionally, it is found that the impact velocities significantly influence the amplitude of motion responses and they increases almost proportionally with the impact velocities rising. It is noticed that for impact velocity of $2 \mathrm{~m} / \mathrm{s}$ in still water, minor responses on platform motions are caused, less than $5 \mathrm{~m}$ in surge motion and $1 \mathrm{deg}$ in pitch motion. For the largest impact velocity $3 \mathrm{~m} / \mathrm{s}$, the maximum motion responses have obviously changed but still in acceptable range for a spar type floating wind turbine. 


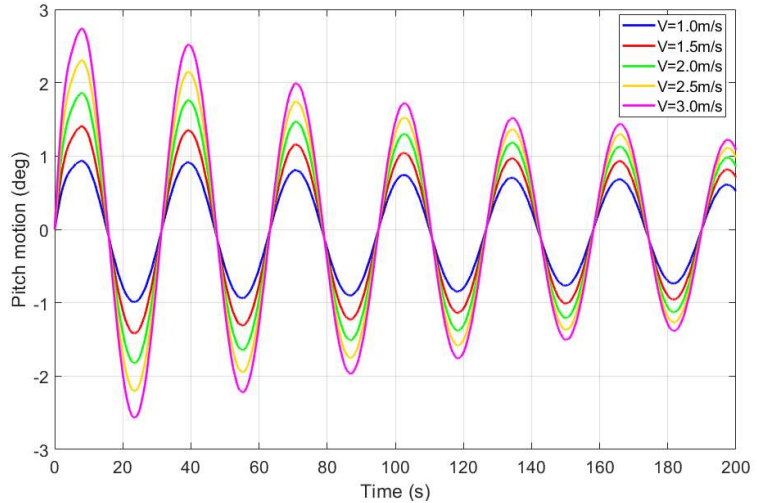

(a) Pitch motion response after collision.

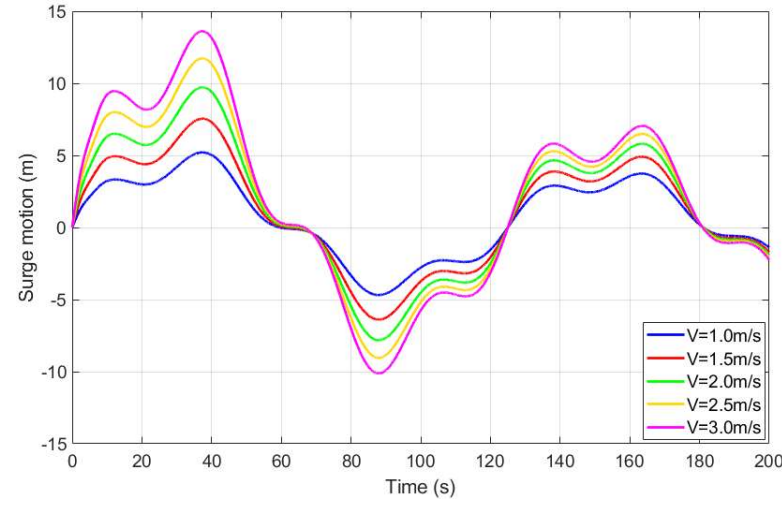

(b) Surge motion responses after collision.

Figure 7. Comparison of motion between collision scenarios with different impact velocities.

Figure 8 illustrates how mooring system responses after the ship impact and Figure 8 (a) presents the time-domain results of tension of fairlead \#1 (the fairlead \#1 is in $X O Z$ plane and has largest responses when undertake ship impact along the direction of surge motion) after collision and Figure 8 (b) illustrates the mooring line responses. It is interesting to find that the fairlead tension shows a periodical decay trend after rapidly rising after ship impact. The mooring system are mainly used to protect the platform from floating away so it should be sensitive to the translational motions of platform, which are also proved by comparing Figure 7 (b) and Figure 8 (a). It is obvious that the overall trend of fairlead tension changes with surge motion (Figure $7 \mathrm{~b}$ ) and the fairlead tension forces reach at the peak where are also the maximum amplitude of surge motions reached.

For the mooring line forces shown in Figure 8 (b), the overall trend and pattern in these five scenarios are similar but in the scenarios with small impact velocity, the fluctuations of mooring line forces seem to be more obvious. It is found that the mooring line forces all increase rapidly though the curves are not so smoothly in the scenarios with velocities from $1.5 \mathrm{~m} / \mathrm{s}$ to $3 \mathrm{~m} / \mathrm{s}$. However, the forces in scenario with impact velocity of $1 \mathrm{~m} / \mathrm{s}$ shows a slight fall before increasing. Additionally, it is found that the period of curves becomes larger in higher impact-velocity scenarios. Considering the surge motions effect on mooring system, it is concluded that the small-range motions caused by the low-speed impact will bring more fluctuations and lower responses period of mooring line forces.

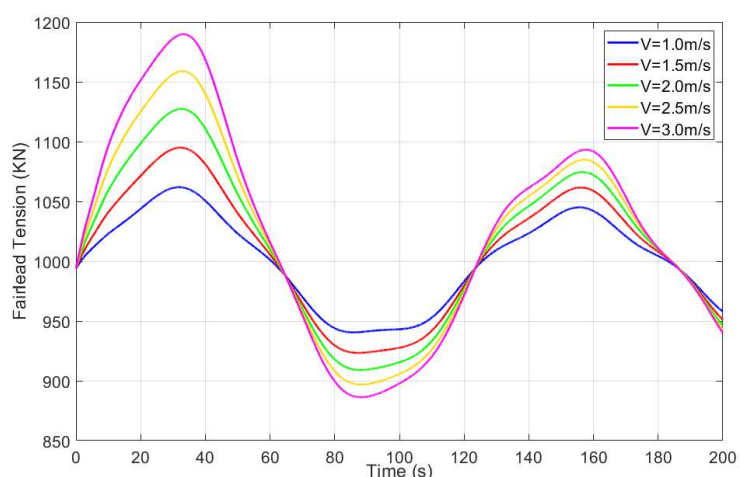

(a) Comparison of fairlead\#1 tension.

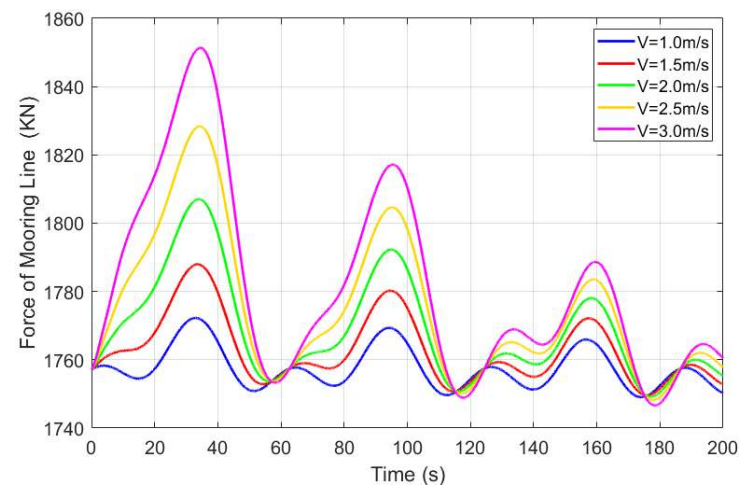

(b) Comparison of mooring line force.

Figure 8. Comparison of tension of fairlead with different impact velocities

Figure 9 (a) gives the motion responses at tower top after ship collision. It is interesting to notice that the tower top motions pattern in surge direction are similar with of platform surge motion, which is shown as Figure 7 (b) but the amplitude in Figure 9 (a) is much bigger, or in other words, comparing with the platform surge motion, the crest and trough in the curves are enhanced. The enhanced crest and trough shown in the curves can be explained by considering the pitch motion coupling effects. As the tower is clamped on the floating platform, the surge motion of platform will directly bring translation motions at tower top, which explains the similar motion pattern between tower top and platform. In the meanwhile, due to the big height of the tower, a slight pitch motion of platform can lead to considerable motion changes at tower top. Thus, when these motions are coupled together, a similar trend with greater amplitude is then formed. Additionally, very slight difference on period is found in each case. This could be explained by considering the flexible tower. Chen et al. [29], Matha et al. [30] found that the elasticity of tower can influence the periods of surge and pitch motion modes. When impact occurs, the tower vibration will be excited and different impact velocity could cause different modes of vibration. The tower top motion is influenced by the coupling effects of platform motion and tower vibration so it turns to have a little different period under different impact velocity. 
The tower vibration can also be found from Figure 9 (b). After the ship impact, the static platform of OFWT gets a velocity and then have periodical decay trend due to the hydrodynamic damping effects. But some small fluctuations are found in Figure 9 (b), which exactly indicates the tower vibration phenomenon. Comparing the responses in different scenarios in Figure 9 , the impact velocities are found still have significant influence on these aspects.

Figure 9 (c) gives a clear sight on acceleration histories and it should be noted that the results presented here represent the responses pattern after ship collision. The acceleration at $\mathrm{t}=0 \mathrm{~s}$, where ship collision ends, is not zero according to the figure. The ship collision is essentially an impulse acting on the spar platform, and the platform then gets increasing momentum. When ship collision process ends, the contact force reduces to zero and platform has gotten a certain velocity. This velocity leads to aerodynamic load on the blades, and hydrodynamic damping load on the spar hull, which gives the initial non-zero acceleration value in Fig.9(c). By considering the coupling effects between platform velocity, vibration of flexible tower, and external forces including aerodynamic, mooring and hydrodynamic aspects, the acceleration at this moment can be calculated by Kane's dynamic equation adopted in DARwind programme. It should be noted that according to Figure 9 (c), the maximum magnitude of acceleration is not at $\mathrm{t}=0 \mathrm{~s}$ but at the next few seconds. At that moment, the nacelle already has a local deflection and keeps vibrating due to the flexible tower. Similar conclusions can also be found from Pedersen's study [37], in which a ship collision against fixed-support wind turbine was analysed. From the numerical simulation results in Pedersen's study, the collision duration can be separated into two phases. In phase 1, the maximum contact force was reached and then fell down but the maximum magnitude of acceleration at nacelle was found during phase 2 when the tower is moving back from the maximum nacelle deflection. In the current study, the scenario where maximum acceleration was reached is similar with that in phase 2 but current results could be a little conservative because the flexibility of tower structure is neglected during the collision process. As for more transient details during collision, they will be included in our next phase of work by using NLFE methods.

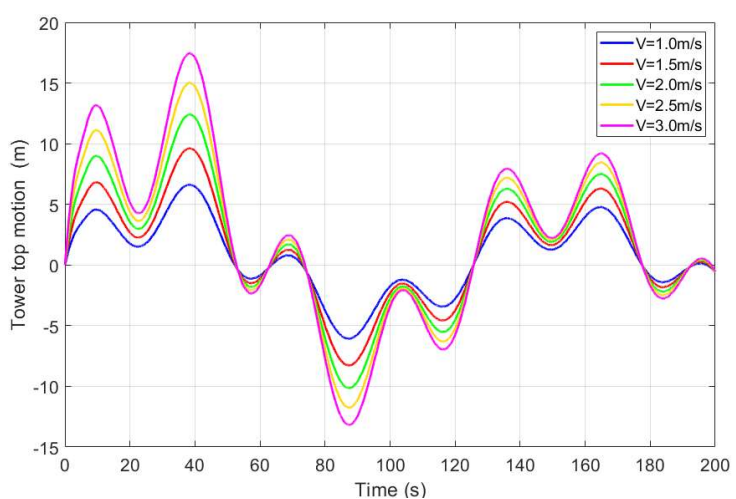

(a) Tower top (nacelle) motion in surge direction.

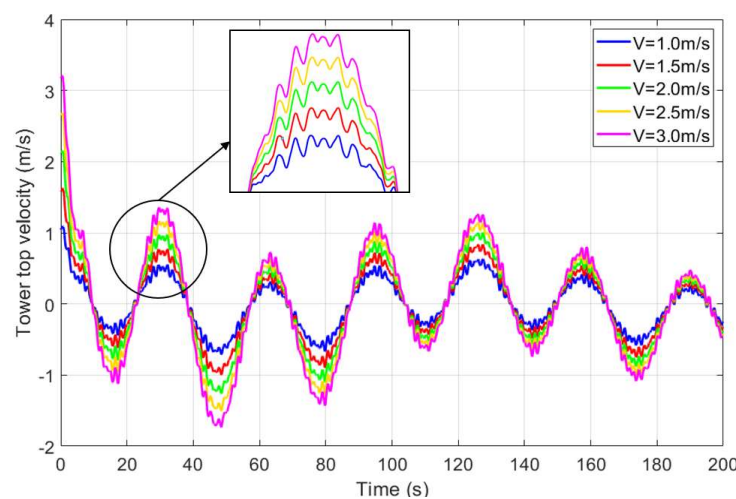

(b) Tower top (nacelle) velocity in surge direction.

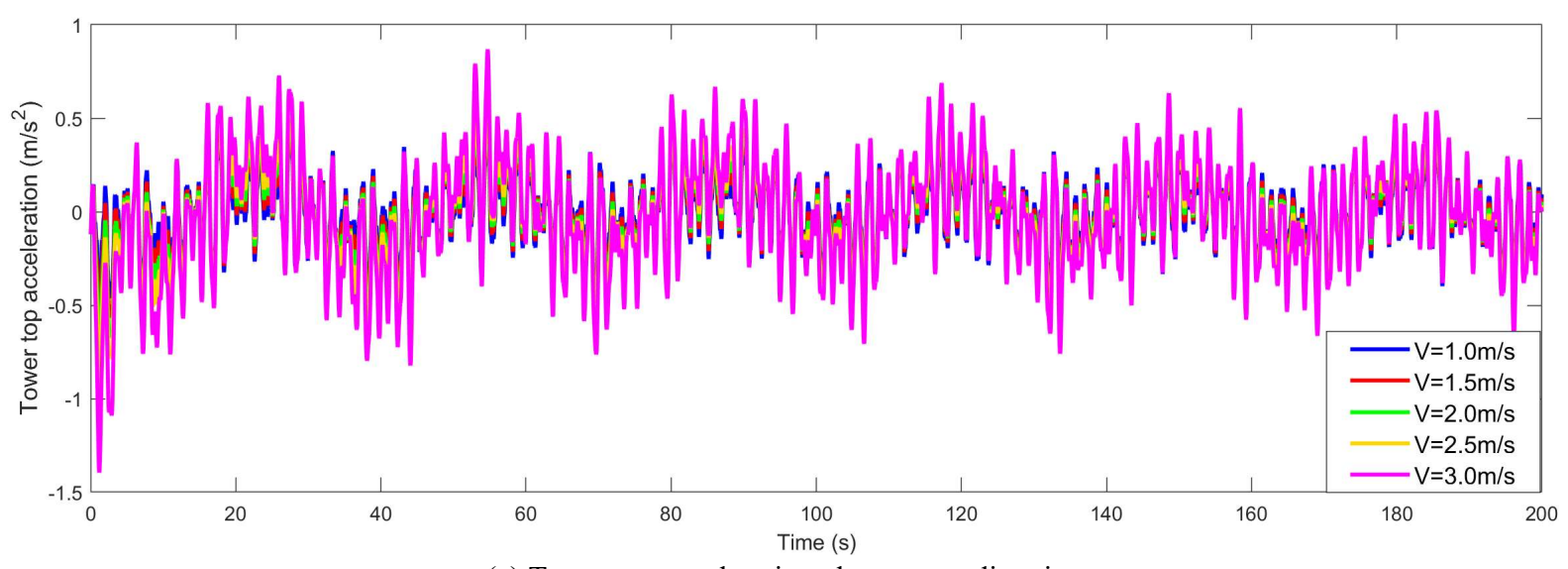

(c) Tower top acceleration along surge direction

Figure 9. The dynamic responses of nacelle under different impact velocities.

To further evaluate the safety of OFWT, the maximum tower tip deformation and acceleration along impact direction are presented as Figure 10. The maximum tower tip deformation here indicates the purely elastic deformation and it clearly show 
a slow growth with the increment of impact velocity when impact velocities are less than $2.5 \mathrm{~m} / \mathrm{s}$. Due to the large mass of rotor-nacelle assembly (RNA), the sudden change of platform motion caused by ship impact will lead to a large inertia force at the tower top, subsequently resulting in structural deformation.

For the maximum acceleration values shown in Fig.10, it appears to have a non-linear rise with impact velocity increasing. The increasing speed also becomes faster at higher impact velocity. The non-linear behaviour is mainly caused by the flexible tower. The acceleration result is obtained from integrated collision analysis model (collision model + DARwind). In DARwind programme, the OFWT is modelled as a rigid-flexible coupled multibody system. Due to the sudden motion change of platform caused by ship impact, the vibration of flexible tower will be excited and bring considerable acceleration. The tower top acceleration depends on the coupling effects of tower vibration as well as the platform motion. This becomes the source of nonlinearity on relationship between tower top acceleration and impact speed. The acceleration at nacelle needs more attention when the crashworthiness of OFWT is taken into consideration during the early designing phase as some equipment in the nacelle might be sensitive to it.

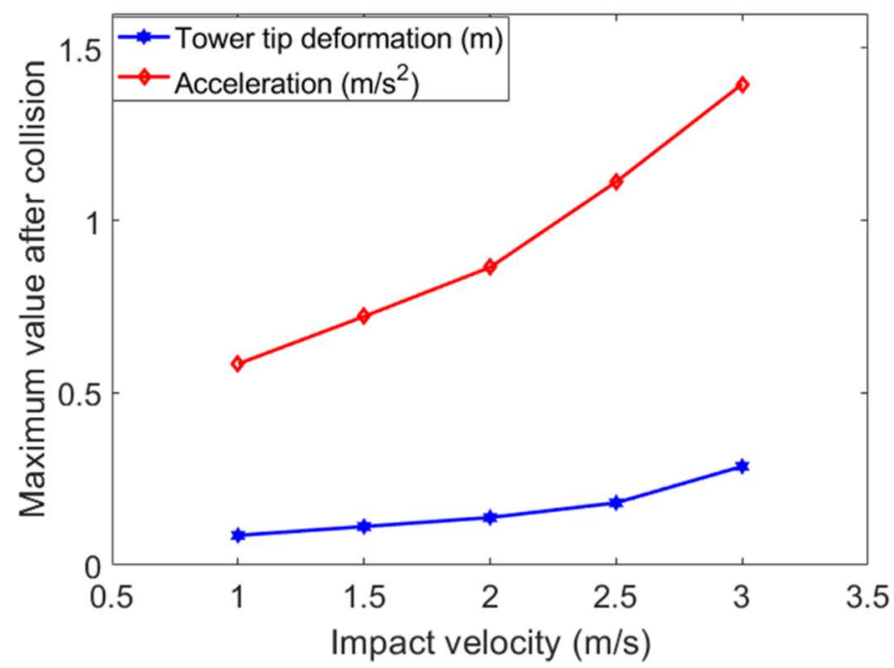

Figure 10. Responses at tower top (nacelle) vs. impact velocity

\subsection{Collision in wave-only condition}

Wave, as a common environmental condition, will brings new loads for the OFWT. Thus the dynamic responses due to ship impact in this type of condition need to be investigated. Figure 11 gives a time-series results of surge motion in wave-only condition without ship collision. In order to have general insight on how ship impact influence the dynamic responses of OFWT, four typically different points are chosen as the ship impact moment, named C1, C2, C3, C4, respectively. The 6DOF motions of OFWT at these impact moments are extracted from Figure 11 and listed in Table 5. Other parameters of these cases have been defined in Table 3 . 


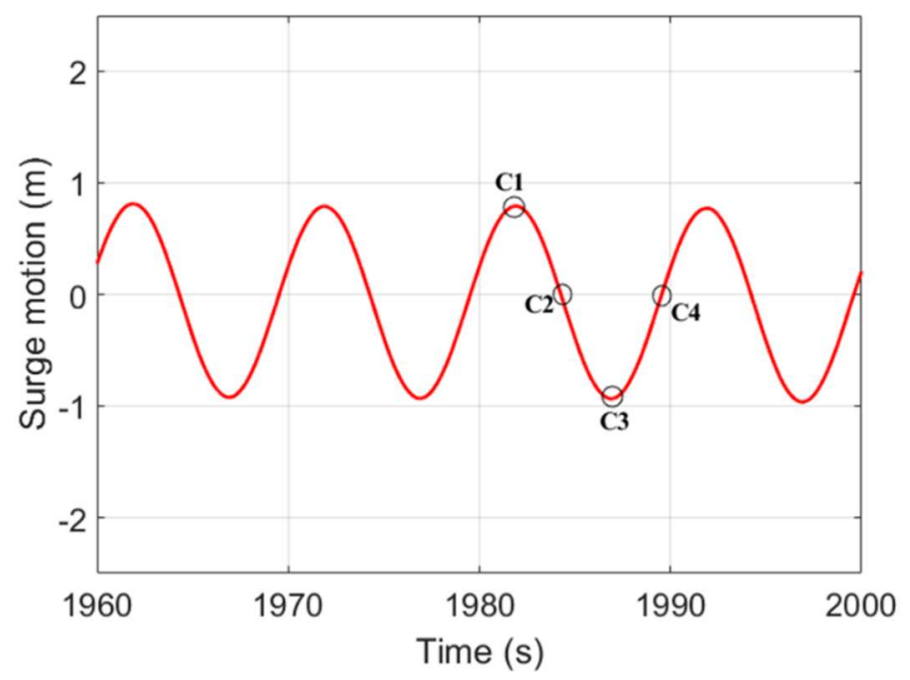

Figure 11. The surge motion in wave-only condition and the definition of impact moments

Table 5. Initial 6DOF motions of OFWT at the impact moment of collision scenarios.

\begin{tabular}{ccccccc}
\hline $\begin{array}{c}\text { Case } \\
\text { Number }\end{array}$ & Surge $(\mathrm{m})$ & Sway $(\mathrm{m})$ & Heave $(\mathrm{m})$ & Roll(deg) & Pitch(deg) & Yaw(deg) \\
\hline C1 & 0.7904 & -0.0384 & -0.2458 & -0.0035 & 0.4021 & -0.0016 \\
C2 & 0.0000 & -0.0124 & -0.4903 & -0.0029 & -0.0251 & 0.0142 \\
C3 & -0.9338 & 0.0231 & -0.4323 & -0.0014 & -0.4784 & -0.0101 \\
C4 & 0.0000 & 0.0547 & -0.2518 & -0.0001 & 0.0205 & -0.0024 \\
\hline
\end{tabular}

The whole time-series results of platform motion responses, including those before and after collision, are shown as Figure 12 and Figure 13. It is noticed that in the first few seconds, the ship collision hasn't occurred, so both the surge motion and pitch motion of OFWT are in the periodical oscillation caused by the regular wave. Due to the sudden ship impact, the platform of OFWT then has a sudden change on its velocity, causing obvious translation (surge) and rotational motions. In the meanwhile, the regular wave still acts on the platform forcing it to oscillate in a small range. For surge motion shown in Figure 12, it is noticed that after collision, though the overall trends are similar, the detailed motion responses, including amplitude and pattern of small fluctuations, are quite different. The most overall motion pattern is mainly caused by the ship impact, and the small spikes shown on the curve are due to the coupling effects of regular wave and pitch motion. For pitch motion responses presented in Figure 13, similarly with the surge motion, obvious motion increment in pitch direction after ship impact are found and a lot of spikes exists in their motion curves due to the regular wave as well.

Though the ship velocity and wave condition are defined as the same in these four cases, the OFWT has different motions with different velocities at the moment of collision, which leads to different relative impact velocity (total impact energy) and will surely cause different values of motion responses accordingly. It is interesting to find that the gap of surge motions in the four cases are slight (the maximum values are all around $5 \mathrm{~m}$ ) compared with that of pitch motion. Obviously, the maximum amplitude of pitch motion responses in case $\mathrm{C} 2$ are much smaller compared with those of the other 3 cases. This indicates that in the wave-only condition, responses of surge motion due to ship impact are less affected by the initial state of OFWT while pitch motion responses of OFWT could also be influenced by the its initial state when ship impact occurs. Additionally, by comparing Figure 7 with Figure 12, 13. Another interesting finding is that for the same ship impact velocity, $3 \mathrm{~m} / \mathrm{s}$, the maximum amplitude of both surge and pitch motions in wave-only condition are generally less than those in still water. The regular wave brings additional resistance during the motion of OFWT after ship collision, which takes more kinetic energy away. 


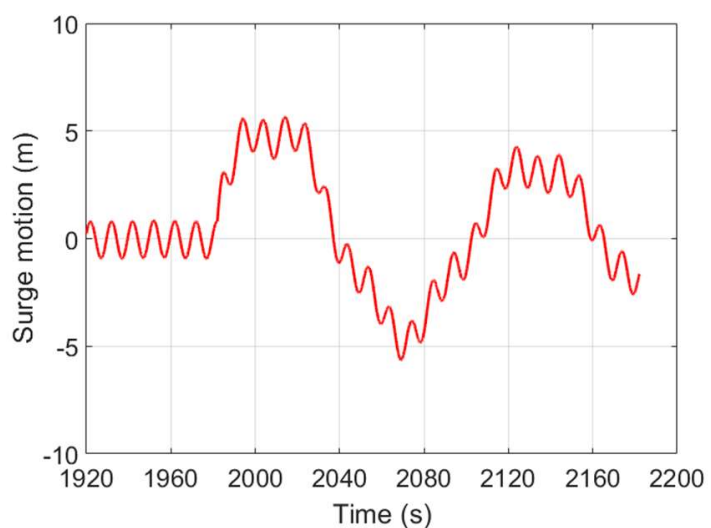

(a) $\mathrm{C} 1$

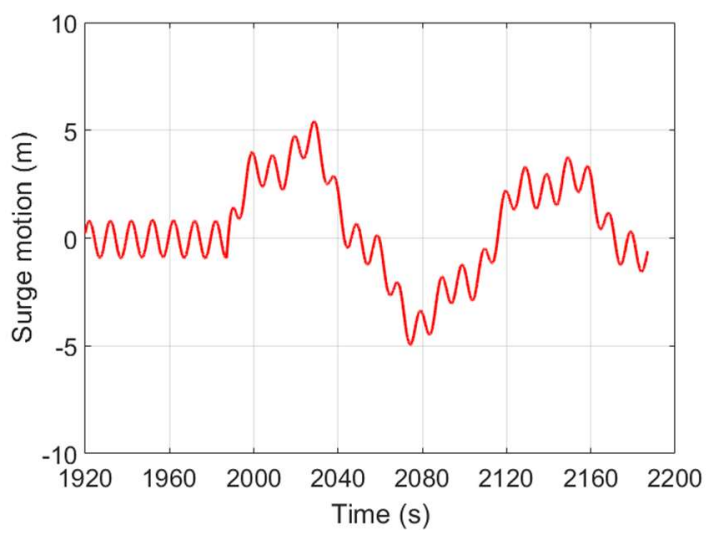

(c) $\mathrm{C} 3$

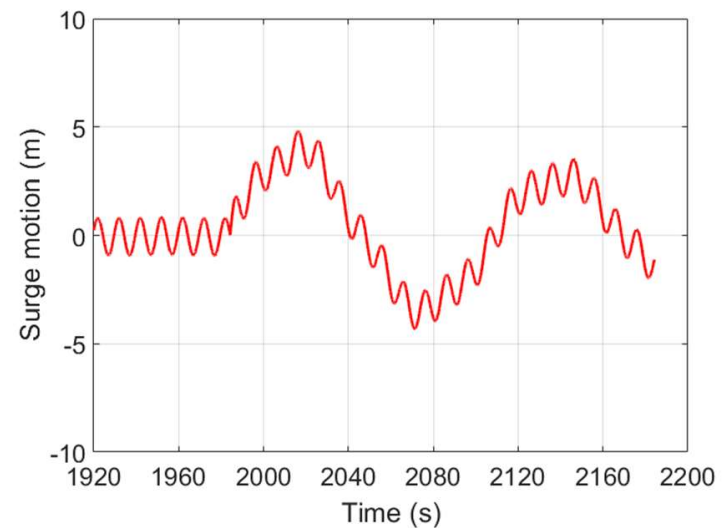

(b) $\mathrm{C} 2$

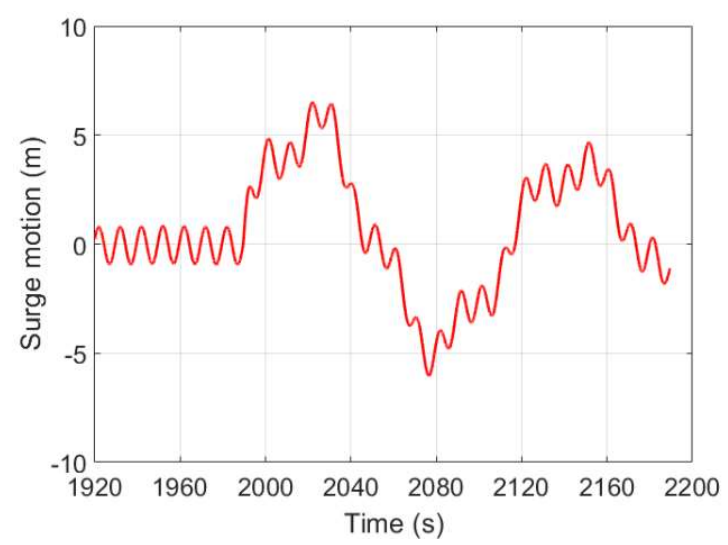

(d) $\mathrm{C} 4$

Figure 12. Surge motion for four collision scenarios in wave-only condition.

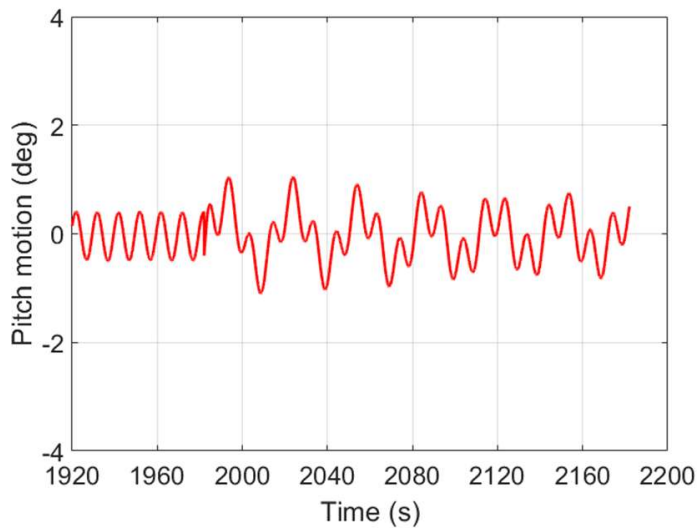

(a) $\mathrm{Cl}$

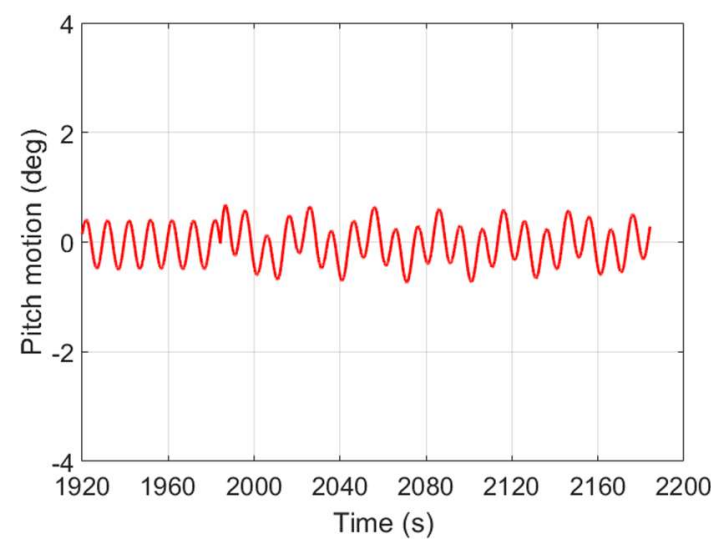

(b) $\mathrm{C} 2$ 


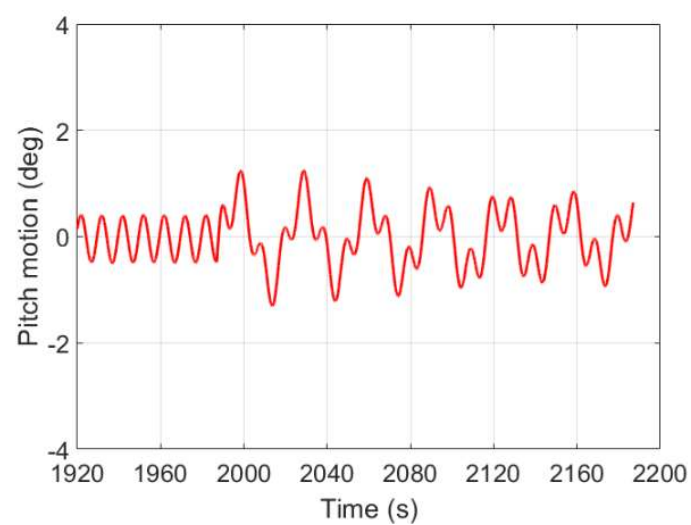

(c) $\mathrm{C} 3$

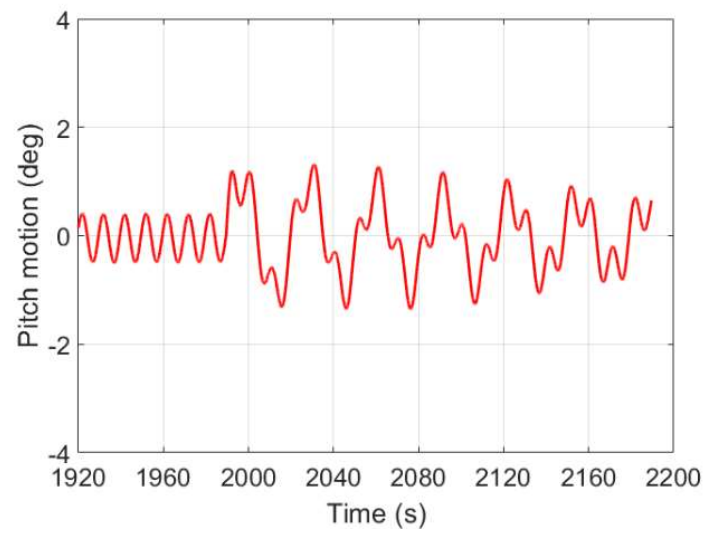

(d) $\mathrm{C} 4$

Figure 13. Pitch motion for four collision scenarios in wave-only condition.

As for the responses at tower top in wave-only condition, a comparison of maximum deformation before and between collision are presented, shown as Figure 14. As is analyzed before, the elastic deformation is mainly caused by tower vibration and the large inertia force at tower top. Due to ship collision, the platform has a sudden change of motion, enhancing the tower vibration. The increasing rates of tower tip deformation after collision are read as $54.2 \%, 51.2 \%, 62.7 \%, 77.3 \%$, respectively. Considering the tower vibration and platform motion, the maximum acceleration after collision are calculated and presented in Table 6 . These values in different cases don't show obvious gap and are all less than suggested safe line $0.2-0.3 g$, where $g$ is the gravitational acceleration. In general, the nacelle is thought to be safe and can withstand this kind of ship impact. More attention needs to be paid to structural responses in the future. Mooring system mainly provides the restoring forces for floating platform to keep them stable. As the platform has obvious growth on their motions after collision, the responses of mooring line forces and fairlead tension need to be compared, shown as Figure 15. The maximum tension at fairlead rises more apparently and rises by $11.99 \%$ in average while the maximum tension of mooring line has a slight average increment rate at $1.11 \%$. It is noticed that the maximum values for both fairlead and mooring line appear in case $\mathrm{C} 4$, where the most obvious motion changes occur after collision. For the safety evaluation, these peak values are still in a normal range and don't need extra attention.

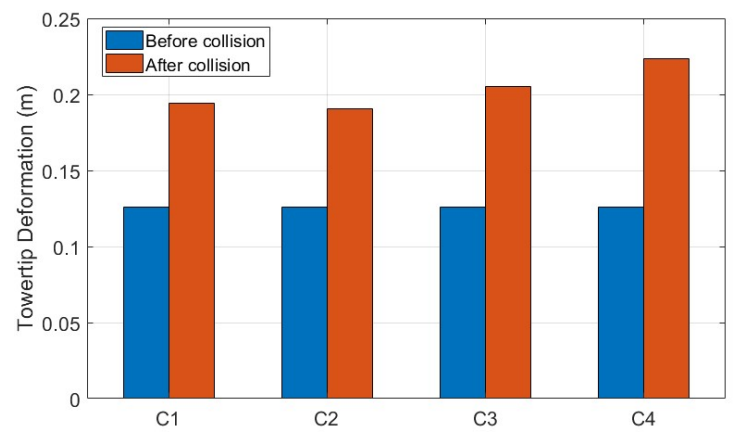

Figure 14. Comparison of maximum tower tip deformation.

Table 6. The maximum accelerations at tower top after ship impact.

\begin{tabular}{lcccc}
\hline Impact scenarios & $\mathrm{C} 1$ & $\mathrm{C} 2$ & $\mathrm{C} 3$ & $\mathrm{C} 4$ \\
\hline Maximum acceleration $\left(\mathrm{m} / \mathrm{s}^{\wedge} 2\right)$ & 1.0495 & 1.1412 & 1.4334 & 1.3065 \\
\hline
\end{tabular}




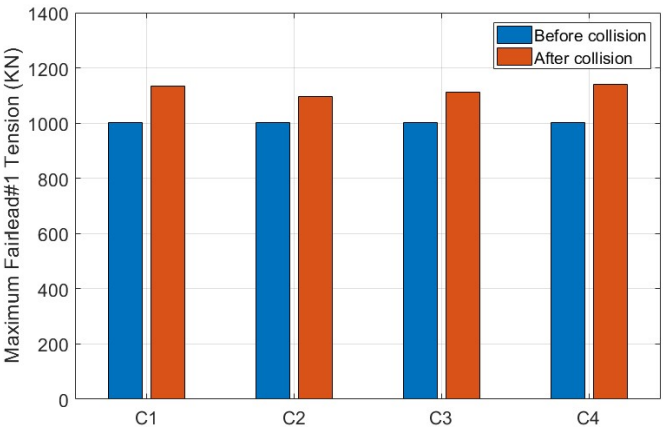

(a) Comparison of maximum tension at fairlead \#1.

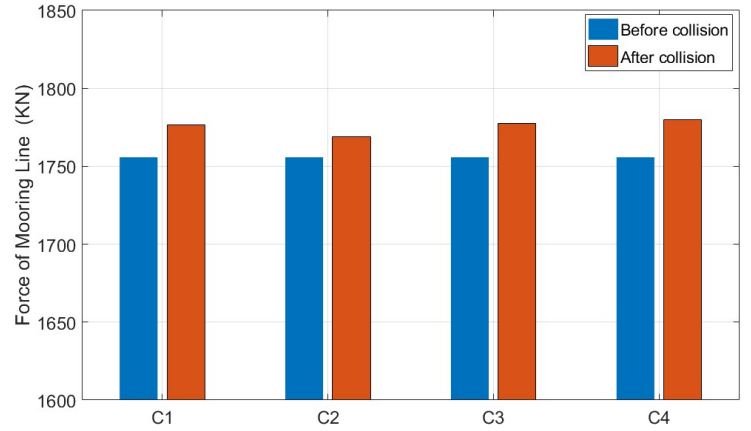

(b) Comparison of maximum mooring line force.

Figure 15. Comparison of mooring system.

\subsection{Collision in wave-wind combined condition.}

Wave-wind combined condition is common for OFWT but also brings new challenge for the investigation of dynamic responses of collision scenarios. The impact loads are more complicated and the dynamic responses might be more difficult to predict. In this section, in order to investigate the general features of OFWT in wind-wave condition under ship collision, a certain period of full-coupled simulation by DARwind was conducted firstly and 5 typical cases, C1-C5, which indicated different collision moments, are selected from a period, shown as Figure 16. The detailed motion in 6DOF at the collision moment are listed in Table 7 and other parameters of environmental condition are defined in Table 3.

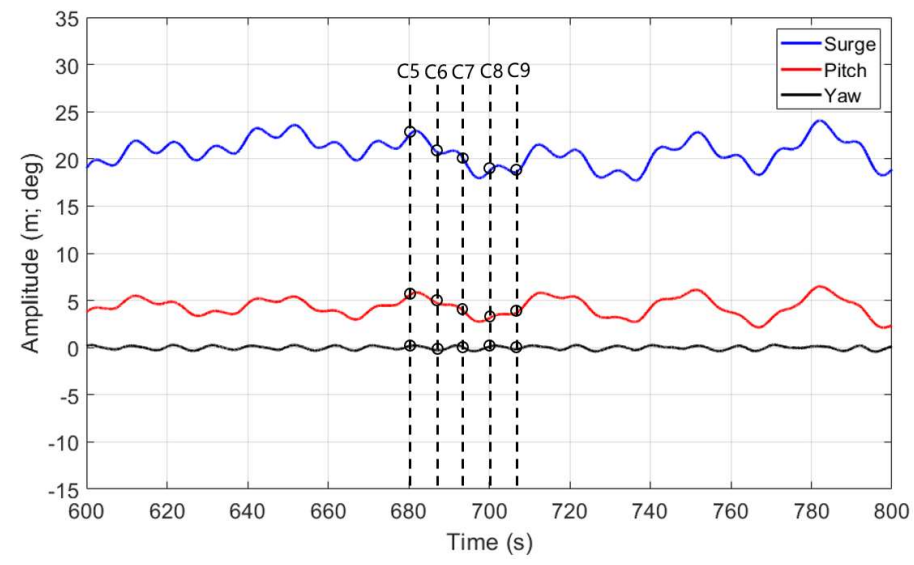

Figure 16. Motions in wave-wave combined condition.

Table 7. Initial 6DOF motions of OFWT at the moment of collision.

\begin{tabular}{ccccccc}
\hline $\begin{array}{c}\text { Case } \\
\text { Number }\end{array}$ & Surge $(\mathrm{m})$ & Sway $(\mathrm{m})$ & Heave $(\mathrm{m})$ & Roll(deg) & Pitch(deg) & Yaw(deg) \\
\hline C5 & 22.4308 & -0.2099 & -0.2593 & 0.0853 & 5.4883 & 0.1490 \\
C6 & 20.8388 & -0.4088 & -0.7080 & -0.2709 & 4.7906 & -0.2773 \\
C7 & 20.2062 & -0.4589 & -1.1465 & 0.3241 & 4.0128 & 0.0804 \\
C8 & 18.6727 & -0.3033 & -0.8146 & 0.1751 & 3.1094 & 0.0887 \\
C9 & 18.5813 & -0.1346 & -0.7132 & 0.0141 & 3.6518 & -0.1935 \\
\hline
\end{tabular}

The motions in wave-wind condition without ship collision are set as a reference to help us have direct insight on how platform responses after collision and the comparison between collision case and reference are presented in Figure 17. As the wind loads are introduced in these four cases, it is noticed that both surge and pitch motion keep periodically moving around a certain value rather than zero and the small fluctuations are mainly due to the regular wave. It is interesting to find that the yaw motion are also obvious in addition to the surge and pitch motion and this is affected by the so-called gyroscopic moments. As the wind were considered in this section, the rotor of OFWT then had rotational motion. The rotational rotor combining 
the platform pitch motion will then excite the gyroscopic moments and enhance the yaw motion of platform.

After collision, it is observed that no matter in which case, surge motions and pitch motions all have obvious increment along the ship-impact direction immediately after ship impact. But it is interesting to find that the maximum values of pitch motions after collision in some cases, such as C6, C7 are less than reference. In other words, after collision, though the pitch motions rise immediately compared with those in scenarios without collision, but they cannot reach to the largest pitch motion that they should have reached without collision. This could be explained by considering the aerodynamic loads. As the impact suddenly enhance the pitch and surge velocity of platform, the velocities at rotor plane changes accordingly, then the wind loads acting on rotor plane changes as well, so the pitch moment induced by wind varies. If the motion effects caused by ship impact cannot offset the loss of wind loads, then the pitch motion in collision scenario may not reach at the maximum value in non-collision scenario even though the pitch motion will increase during a short time after collision.

It is interesting to find that the yaw motions also change after collision though the ship impacts along the surge direction and this can be understood by considering the change of gyroscopic moments. Ship impact along the surge direction shouldn't have influenced the yaw motion of OFWT directly, but as a rigid-flexible coupled multi-body, the loads and structures always have interaction. The change of platform motions due to ship impact influence the motion of rotor-nacelle assembly, subsequently affecting aerodynamic loads. Finally, the combined effects of the change from aerodynamic loads, mooring loads as well as pitch motions results in the varying of gyroscopic moments.

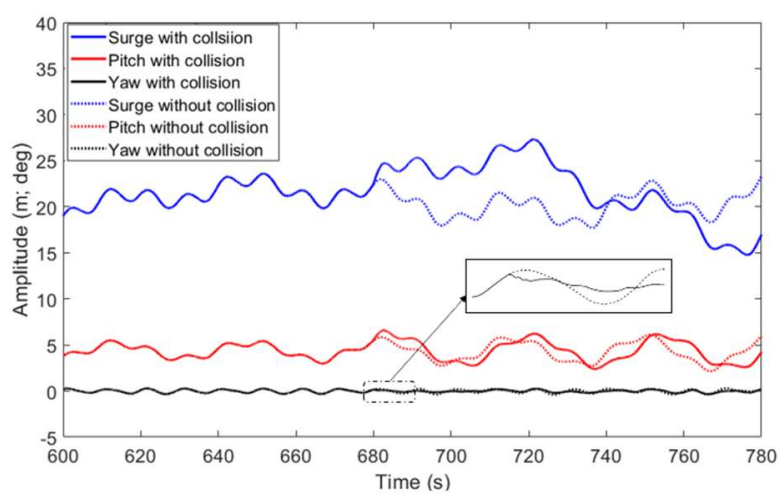

(a). C5

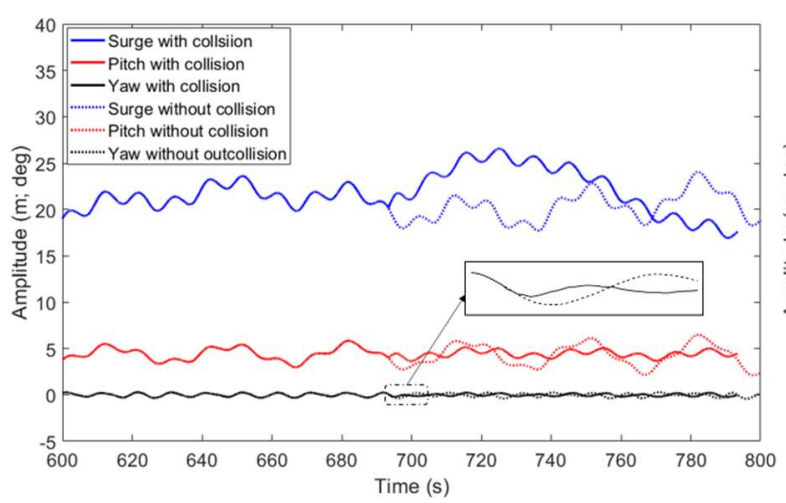

(c). $\mathrm{C} 7$

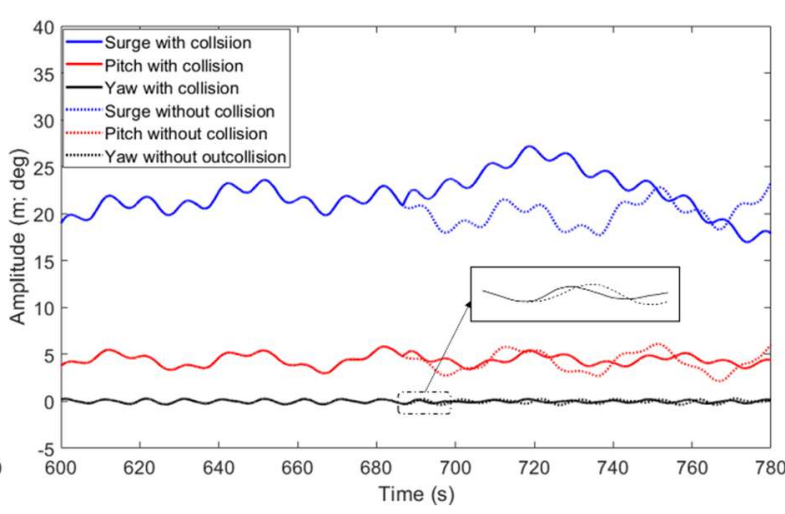

(b). C6

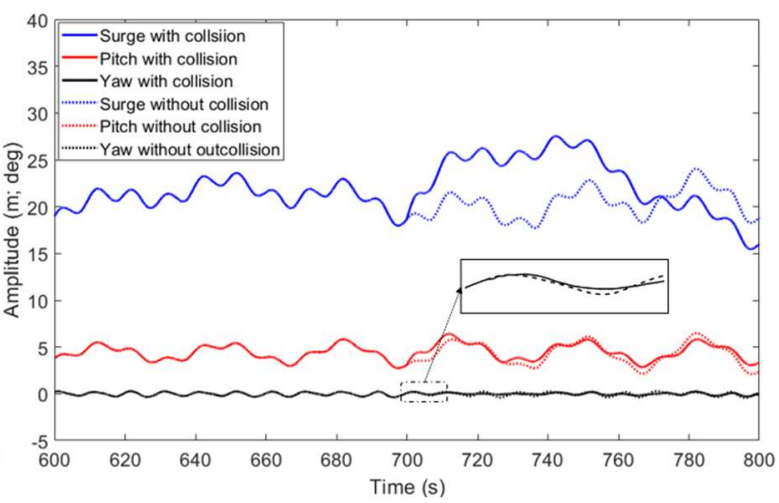

(d). C8 


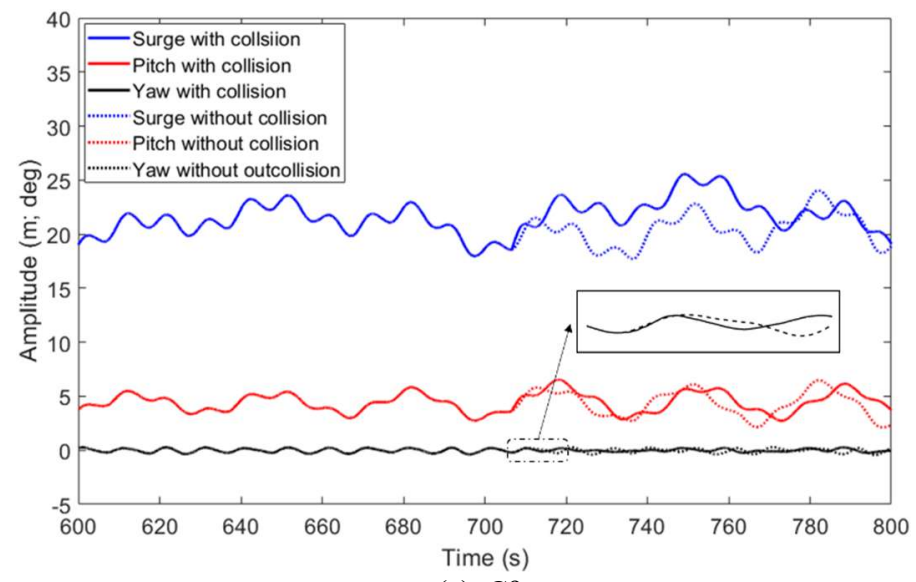

(e). C9.

Figure 17. Motions comparison between collision scenarios and reference scenario for case C5-C9.
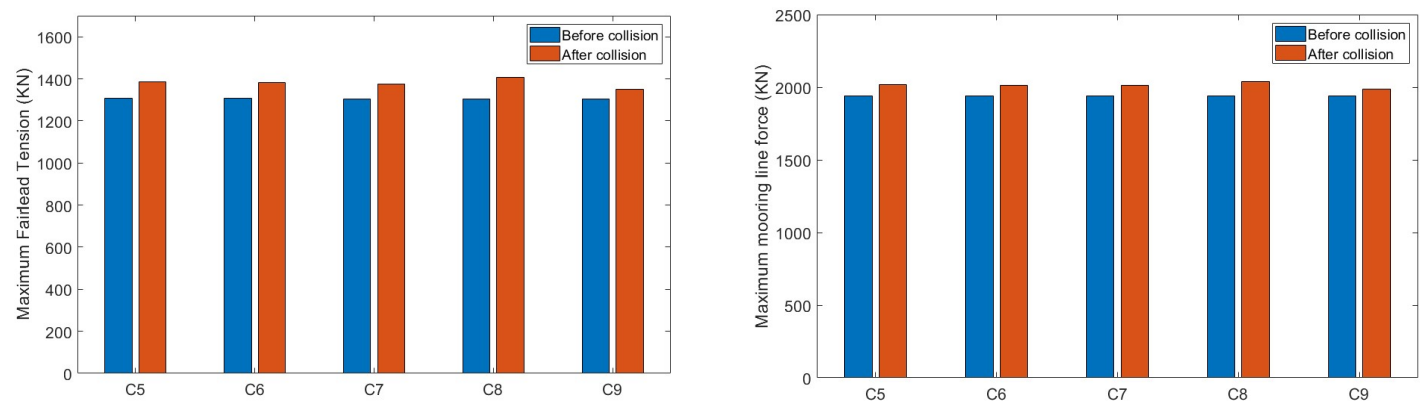

Figure 18. Comparison of maximum responses of mooring system before and after ship collision.

The maximum fairlead tension as well as mooring line force before and after collision in wave-wind condition are compared as Figure 18. These forces from mooring system are mainly governed by platform translation motions. The largest change occurs in case $\mathrm{C} 8$, where the surge motions also increase the most. Because of the combination of wave and wind, the surge and pitch motions are already kept at a relatively high value, where large tension forces exist at fairlead and mooring line. Thus, the increment due to ship impact are not so obvious. The average increasing rate for fairlead tension and mooring line force are found at $5.76 \%$ and $3.72 \%$. the maximum fairlead tension and mooring line forces reaches at around $1410 \mathrm{kN}$ and $2092 \mathrm{kN}$ respectively, which are much larger than those in still water and wave-only condition. Though they are in an acceptable range in the current cases(with impact velocities of $3 \mathrm{~m} / \mathrm{s}$ ), the mooring strength after ship collision in wave-only condition still need more attention as the typical impact velocity for a OSV could reach at $5 \mathrm{~m} / \mathrm{s}$.

Aerodynamic thrust loads on rotor in these five cases are presented in Figure 19. It is interesting to find that the rotor thrust force in each case shows a regular pattern with respect to time before collision. The rotor thrust force pattern before collision could be different by using different simulation tool. For example, in some other common simulation tool for OFWT, such as FAST [30], the rotor thrust force could be constant and this is due to the different control strategy. In FAST, the generatortorque controller and the blade-pitch controller are combined to work together in order to maintain the power above the rated condition. However, in DARwind code, a typical-variable control scheme is used when above the rated condition. In that case, the generator-torque controller will maintain the nominal value of torque and only blade-pitch controller works to regulate the rotor speed. This will bring varying power and aerodynamic load on the rotor but it could help reduce the fatigue damage of shaft due to the constant generator torque.

After ship impact, the sudden reduction of the thrust force mainly results from the change of motion and velocity at rotor plane. The analysing program adopted BEM methods to evaluate the aerodynamic load, and in this method, the thrust force acting on each blade elements depends more on the relative incident velocity. Due to the ship impact, the platform motion and velocities in surge and pitch direction will immediately rises along the ship impact direction. As is connected by the tower to the platform, the rotor-nacelle assembly will then get a growth on its velocity along ship impact, which is the same as the wind speed. As a consequent, the relative velocity at blade elements decreased in a short time after collision and results in the transient fall of rotor thrust force. Later, due to the control strategy and coupling effects between each component, the thrust force at rotor plane will get adjusted and gradually recover to its normal responses pattern. 
Additionally, due to the complicated conditions and ship impact, the responses of flexible-modelled bodies, tower and blades need to be analyzed. A comparison of them before and after collision are listed in Table 8. BtDefx and BtDefy refers to the blade tip deformation along the $\mathrm{x}$-axis and $\mathrm{y}$-axis, respectively, which are also called flapwise tip deformation (outside the rotor plane) and edgewise tip deformation (inside the rotor plane). TtDefx represents the tower tip deformation along the $\mathrm{x}$ axis, same as the surge motion. It is noticed that the maximum tower tip deformation in all cases grow after the ship collision. This could be simple to understand because the tower is like a flexible beam which is clamped on the platform and has a lumped mass on the top. Ship collision gives the platform a sudden velocity and motion change, which will induce large inertia force on the top. Thus, maximum deformation on the top rises. For blade flapwise vibration, they are more obvious than edgewise vibration but the increasing rate of maximum amplitude after collision are less than that in edgewise direction, over $20 \%$ in most cases. As the edgewise vibration is mainly governed by the rotor rotation, after the ship collision, the aerodynamic loads acting on rotor fall rapidly and the rotational speed of rotor changes accordingly. Due to the sudden change of rotational speed of rotor, there will be a considerable inertia force acting on blade root in the rotor plane, which results in the large increment of edgewise tip deformation.

Considering all the loads and structural coupled effects, the maximum accelerations of nacelle in these 5 cases are presented in Table 9. It is noticed that in the wind-wave combined condition plus ship impact, the maximum accelerations at tower top are extremely large compared with those in still water and wave-only condition. This could be caused by considering the aerodynamic loads. The wind thrust loads are huge enough according to Fig. 19 and they mainly acts on the rotor plane. Due to the vertical eccentricity, the pitch motion will be enhanced. If the ship impact occurs in this scenario with a same direction of wind, the transient acceleration at tower top must be very large due to the coupling effects of wind thrust loads and ship impact. According to Table 9, these acceleration are much larger than the suggested limitation [15], 0.2-0.3g, where $\mathrm{g}$ is the gravitational acceleration. In this case, the equipment in the nacelle might fail to work but the detailed responses cannot be exactly simulated in the current study.
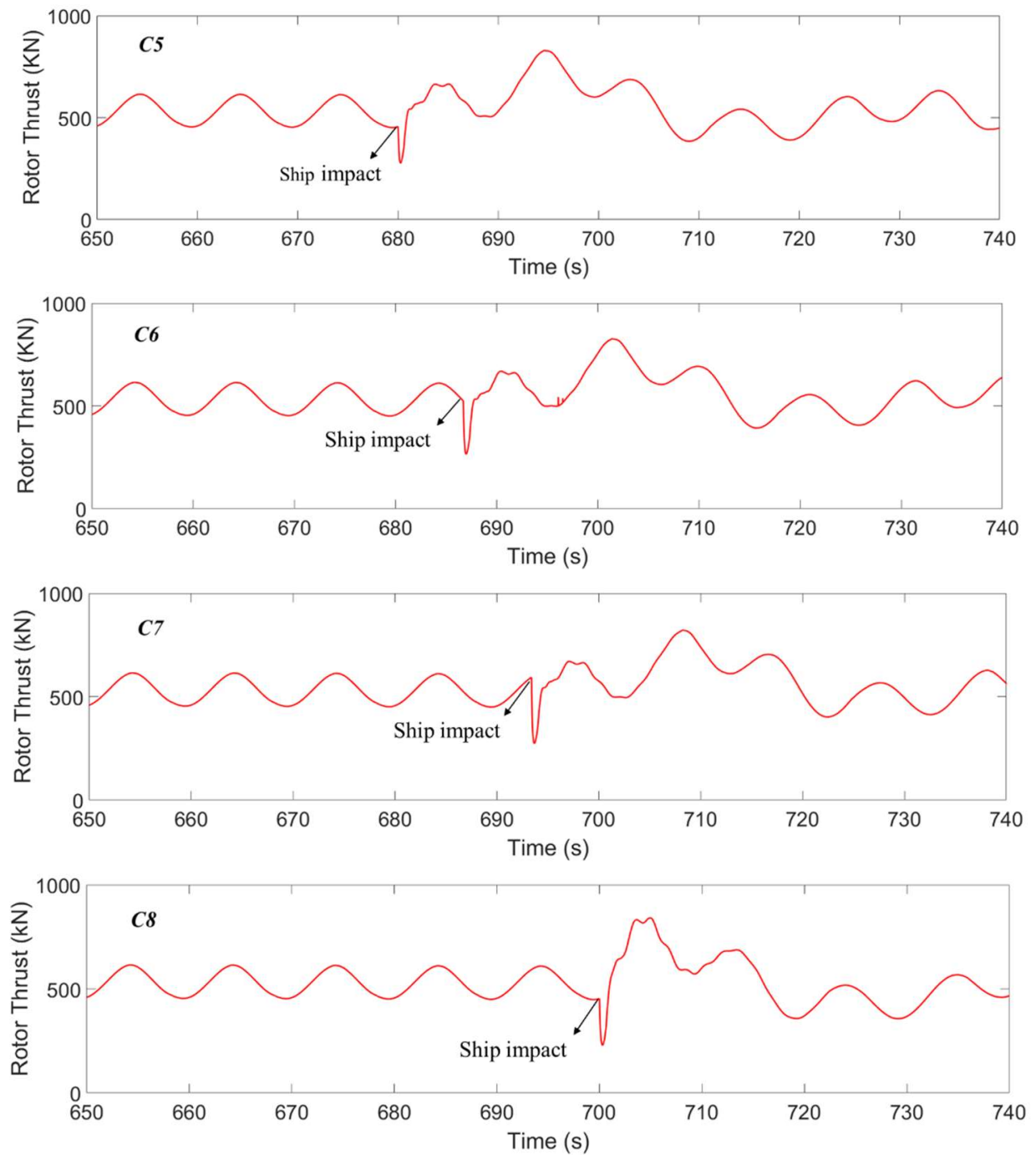


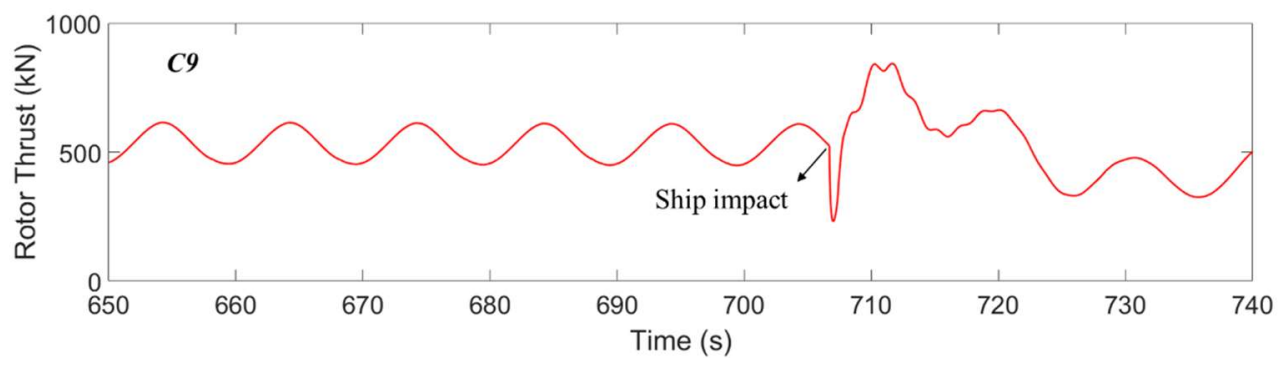

Figure 19. Responses of rotor thrust in ship-collision scenarios

Table 8. Comparison of blade and tower tip deformation

\begin{tabular}{|c|c|c|c|c|}
\hline \multicolumn{2}{|c|}{} & Before Collision & After Collision & Increasing rate \\
\hline \multirow{4}{*}{ C5 } & Maximum BtDefx (m) & 5.9637 & 6.3548 & $6.15 \%$ \\
\cline { 2 - 2 } & Maximum BtDefy (m) & 0.4955 & 0.6449 & $23.17 \%$ \\
\cline { 2 - 2 } & Maximum TtDefx (m) & 0.5366 & 0.7012 & $23.47 \%$ \\
\hline \multirow{4}{*}{ C6 } & Maximum BtDefx (m) & 5.9637 & 5.7645 & $-3.46 \%$ \\
\cline { 2 - 2 } & Maximum BtDefy (m) & 0.4955 & 0.6580 & $24.70 \%$ \\
\cline { 2 - 2 } & Maximum TtDefx (m) & 0.5366 & 0.6567 & $18.29 \%$ \\
\hline \multirow{4}{*}{ C7 } & Maximum BtDefx (m) & 5.9916 & 5.9049 & $-1.47 \%$ \\
\cline { 2 - 2 } & Maximum BtDefy (m) & 0.4955 & 0.5599 & $11.50 \%$ \\
\cline { 2 - 2 } C8 & Maximum TtDefx (m) & 0.5366 & 0.6242 & $14.03 \%$ \\
\cline { 2 - 2 } & Maximum BtDefx (m) & 5.9916 & 6.2900 & $4.74 \%$ \\
\cline { 2 - 2 } & Maximum BtDefy (m) & 0.5136 & 0.6961 & $26.22 \%$ \\
\hline \multirow{3}{*}{ C9 } & Maximum TtDefx (m) & 0.5366 & 0.6075 & $11.67 \%$ \\
\cline { 2 - 2 } & Maximum BtDefx (m) & 5.9916 & 6.1974 & $3.32 \%$ \\
\cline { 2 - 2 } & Maximum BtDefy (m) & 0.5136 & 0.6782 & $24.27 \%$ \\
\cline { 2 - 2 } & Maximum TtDefx (m) & 0.5366 & 0.5891 & $8.91 \%$ \\
\hline
\end{tabular}

Table 9. Maximum acceleration at tower top.

\begin{tabular}{lccccc}
\hline Impact scenarios & C5 & C6 & C7 & C8 & C9 \\
\hline Maximum acceleration $\left(\mathrm{m} / \mathrm{s}^{\wedge} 2\right)$ & 14.0387 & 7.6524 & 10.9701 & 10.8619 & 8.7272 \\
\hline
\end{tabular}

\section{Conclusion}

This paper proposes a dynamic responses analysis model for OFWT in the scenario of ship collision. A 3D transient collision model based on previous studies are further applied onto the collision analysis between a ship and a Spar-type floating wind turbine. This collision model was combined with DARwind, an in-house program developed for aero-hydro-servo-elastic coupled analysis of offshore wind turbine. With this combined method, the external dynamic responses of an OC3 Hywind spar floating wind turbine which was impacted by an offshore service vessel were calculated and analyzed.

1) In the still water condition, the impact velocity has significant influence on the dynamic responses of OFWT. the maximum amplitude in platform motions almost increase proportionally with the impact velocity rising. The responses of mooring system as well as accelerations at the tower top also have huge change but they are still within a safe range even for a head-on collision with initial velocity of $3 \mathrm{~m} / \mathrm{s}$.

2) In the wave-only condition, four cases were selected and the platform motions before and after ship collision were demonstrated. The increment of motions in surge and pitch direction after collision are obvious but smaller than those responses in still water. Additionally, the ship collision can enhance the amplitude of the tower vibration. The maximum tower tip deformation along collision direction changes dramatically, increasing by over $50 \%$ in four cases. The maximum axisaccelerations at the nacelle in these four cases are found to be a slightly larger than those in still water, but still less than the suggested safe line, $0.2 \mathrm{~g}-0.3 \mathrm{~g}$, where $\mathrm{g}$ is the gravitational acceleration. 
3) In the wind-wave condition, the increment of surge and pitch motion after collision are not so large compared with cases in still water and wave-only condition. The mooring line tension and fairlead tension after ship impact have slightly increasing rate, at around $3 \%-7 \%$ but the actual value of mooring line tension has reached almost $3000 \mathrm{kN}$. the wind loads acting on the rotor drop dramatically after collision. The change of aerodynamic loads further influences the gyroscopic moment and the yaw motion has obvious change accordingly. The blade tip deformation in rotor plane is influenced the most by ship impact, owning an overall increasing rate larger than $20 \%$. The axis-accelerations of generator at nacelle in these cases are found all very huge, mostly larger than $9 \mathrm{~m} / \mathrm{s}$, meaning that even we ignore the structural damage due to ship impact, the huge accelerations at nacelle may still result in the failure of equipment.

4) Currently, the combined method used in this paper is only able to address the external dynamic responses analysis of OFWT during scenarios of ship impact. The significant features of OFWT can mostly be considered and analysed before and after ship collision to help understand how OFWT responses after collision. Some safety assessment was also considered by analysing the maximum elastic structural deformation or accelerations at nacelle, but these are based on ignoring the structural damage due to ship impact. A method considering both external and internal structural dynamic responses will be developed in the future.

\section{References}

1. GWEC, G. W. E. C. (2019). Global wind report. 2018. Brussels: GWEC.

2. Christensen, C.F., Andersen, L.W. and Pedersen, P.H., 2001. Ship collision risk for an offshore wind farm. In Structural Safety and Reliability: Proceedings of the Eighth International Conference, ICOSSAR (Vol. 1).

3. Biehl, F. and Lehmann, E., 2006, January. Collisions of Ships and Offshore Wind Turbines: Calculation and Risk Evaluation. In 25th International Conference on Offshore Mechanics and Arctic Engineering (pp. 663-670). American Society of Mechanical Engineers.

4. Dai, L., Ehlers, S., Rausand, M. and Utne, I.B., 2013. Risk of collision between service vessels and offshore wind turbines. Reliability Engineering \& System Safety, 109, pp.18-31.

5. Presencia, C.E. and Shafiee, M., 2018. Risk analysis of maintenance ship collisions with offshore wind turbines. International Journal of Sustainable Energy, 37(6), pp.576-596.

6. Caithness Windfarm Information Forum n.d., Wind turbine accident compilation. Available from: http://www.caithnesswindfarms.co.uk/AccidentStatistics.htm [5 January. 2020]

7. Biehl, F., 2005. Collision safety analysis of offshore wind turbines. In 4th LS-DYNA European Conference.

8. Le Sourne, H., Barrera, A. and Maliakel, J.B., 2015. Numerical crashworthiness analysis of an offshore wind turbine jacket impacted by a ship. Journal of Marine Science and Technology, 23(5), pp.694-704.

9. Moulas, D., Shafiee, M. and Mehmanparast, A., 2017. Damage analysis of ship collisions with offshore wind turbine foundations. Ocean Engineering, 143, pp.149-162.

10. Bela, A., Le Sourne, H., Buldgen, L. and Rigo, P., 2017. Ship collision analysis on offshore wind turbine monopile foundations. Marine Structures, 51, pp.220-241.

11. Jones, N., 2011. Structural impact. Cambridge university press.

12. Pire, T., Le Sourne, H., Echeverry, S. and Rigo, P., 2018. Analytical formulations to assess the energy dissipated at the base of an offshore wind turbine jacket impacted by a ship. Marine Structures, 59, pp.192-218.

13. DNV, 2014. DNV-OS-J101-Design of offshore wind turbine structures.

14. DNV, 2013. DNV-OS-J103-Design of floating wind turbine structures.

15. Echeverry, S., Márquez, L., Rigo, P. and Le Sourne, H., 2019. Numerical crashworthiness analysis of a spar floating offshore wind turbine impacted by a ship. In Developments in the Collision and Grounding of Ships and Offshore Structures: Proceedings of the 8th International Conference on Collision and Grounding of Ships and Offshore Structures (ICCGS 2019), October, 2019, Lisbon, Portugal (p. 85). CRC Press.

16. Stronge, W.J. 2004. Impact mechanics. Cambridge university press.

17. Liu, Z. and Amdahl, J., 2010. A new formulation of the impact mechanics of ship collisions and its application to a ship- 
iceberg collision. Marine Structures, 23(3), pp.360-384.

18. Chen, J., Hu, Z., Liu, G. and Wan, D., 2019. Coupled aero-hydro-servo-elastic methods for floating wind turbines. Renewable energy, 130, pp.139-153.

19. Likins, P.W., 1972. Finite element appendage equations for hybrid coordinate dynamic analysis. International Journal of Solids and Structures, 8(5), pp.709-731.

20. Tupling, S.J. and Pierrynowski, M.R., 1987. Use of cardan angles to locate rigid bodies in three-dimensional space. Medical and Biological Engineering and computing, 25(5), pp.527-532.

21. Hansen M.O., 2008. Aerodynamics of wind turbines: Routledge.

22. M. Masciola, J. Jonkman, A. Robertson, Implementation of a multisegmented, quasi-static cable model, in: Proceedings of the 23th International Offshore and Polar Engineering Conference. International Society of Offshore and Polar Engineers,

23. Kane, T.R. and Levinson, D.A., 1983. The use of Kane's dynamical equations in robotics. The International Journal of Robotics Research, 2(3), pp.3-21.

24. Jonkman, J.M., 2010. Definition of the Floating System for Phase IV of OC3. Golden, CO: National Renewable Energy Laboratory.

25. Jonkman, J.M., et al. 2009. Definition of a 5-MW reference wind turbine for offshore system development. Golden, CO: National Renewable Energy Laboratory.

26. Petersen, M.J. and Pedersen, P.T., 1981, January. Collisions between ships and offshore platforms. In Offshore Technology Conference. Offshore Technology Conference.

27. Pedersen, P.T., Valsgaard, S., Olsen, D. and Spangenberg, S., 1993. Ship impacts: bow collisions. International Journal of Impact Engineering, 13(2), pp.163-187.

28. Popov, Y.N., Faddeev, O.V., Kheisin, D.E. and Yakovlev, A.A., 1969. Strength of ships sailing in ice (No. FSTC-HT-2396-68). ARMY FOREIGN SCIENCE AND TECHNOLOGY CENTER CHARLOTTESVILLE VA.

29. Chen, J., Hu, Z., Liu, G. and Tang, Y., 2017. Comparison of different dynamic models for floating wind turbines. Journal of Renewable and Sustainable Energy, 9(6), p.063304.

30. Matha, D., Fischer, T., Kuhn, M. and Jonkman, J., 2010. Model development and loads analysis of a wind turbine on a floating offshore tension leg platform (No. NREL/CP-500-46725). National Renewable Energy Lab.(NREL), Golden, CO (United States).

31. Le Sourne, H., Pire, T., Hsieh, J.R. and Rigo, P., 2016. New analytical developments to study local and global deformations of an offshore wind turbine jacket impacted by a ship. In Proceedings of the 7th International Conference on Collision and Grounding of Ships and Offshore Structures (ICCGS'16) (pp. 15-18). Ulsan, Korea: University of Ulsan.

32. Bauchau, O.A., 2010. Flexible multibody dynamics (Vol. 176). Springer Science \& Business Media.

33. Faltinsen, O., 1993. Sea loads on ships and offshore structures (Vol. 1). Cambridge university press.

34. Spera, D.A., 1994. Wind turbine technology.

35. Øye, S., 1991, January. Dynamic stall simulated as time lag of separation. In Proceedings of the 4th IEA Symposium on the aerodynamics of wind turbines.

36. Jonge, T.D., Laukeland, L., 2013. Collision between a spar platform and a tanker. Collision and Grounding of Ships and Offshore Structures. Amdahl, J., Ehlers, S., Leira, B., (Eds). Taylor \& Francis Group, London, ISBN 978-1-138-00059-9.

37. Pedersen, P.T., 2013. Ship collisions against wind turbines, quays and bridge piers. Collision and grounding of ships and offshore structures. CRC Press/Taylor and Francis Group, London, pp.273-280. 